\title{
BEL CANTO
}

\section{Years Young: a study in the practical application of bel canto technique to twentieth-century vocal works in English}

By

\section{Pasquale Alexandra Orchard}

An exegesis

submitted to the Victoria University of Wellington in partial fulfilment of the requirements for the degree of Master of Musical Arts

Victoria University of Wellington 
I was born with a voice - but that was not enough to make me a musician or a singer - Montserrat Caballé 


\section{Table of Contents}

$\begin{array}{ll}\text { ACKNOWLEDGEMENTS } & 7\end{array}$

$\begin{array}{lr}\text { CHAPTER ONE: INTRODUCTION } & 9\end{array}$

Origins and development of bel canto 11

$\begin{array}{ll}\text { Methodology } & 17\end{array}$

Anglo-Italian Connections: The teaching of bel canto outside of Italy 19

CHAPTER TWO: DEFINITIONS AND APPROACHES TO BEL CANTO PRINCIPLES 22

$\begin{array}{ll}\text { Individual bel canto Principles } & 24\end{array}$

$\begin{array}{ll}\text { Legato/Sostenuto } & 25\end{array}$

$\begin{array}{ll}\text { Registers } & 28\end{array}$

$\begin{array}{ll}\text { Voce di petto and voce mista } & 30\end{array}$

Breathing and appoggio $\quad 33$

CHAPTER THREE: THOUGHTS ON VOCAL 'PLACEMENT’ FROM WELL KNOWN 37 SINGERS

$\begin{array}{ll}\text { Register Challenges } & 40\end{array}$

$\begin{array}{ll}\text { Chiaroscuro in practice } & 44\end{array}$

Vowels and Diphthongs in the English Language $\quad 46$

CHAPTER FOUR: EXAMINATION OF SELECTED WORKS 52

CHAPTER FIVE: CONCLUSION AND MOVING FORWARD 61

$\begin{array}{ll}\text { APPENDIX: GLOSSARY OF TERMS } & 63\end{array}$

$\begin{array}{ll}\text { BIBLIOGRAPHY } & 65\end{array}$ 


\section{Acknowledgements}

I would first like to thank my thesis supervisor and vocal teacher Jenny Wollerman, Senior

Lecturer in Classical Voice at the New Zealand School of Music, Te Koki at the Victoria University of Wellington. Jenny was always there whenever I ran into trouble or had a question. Thank you for continually inspiring and supporting me.

Thanks are also due to Dr. Margaret Medlyn, Head of Classical Voice Performance for her critical eye and ear, always encouraging me to improve myself as an academic and an aspiring performer.

I acknowledge the support and contribution of my vocal coaches Mark Dorrell, Bruce Greenfield and Amber Rainey. Thank you for your never-ending love: you all went above and beyond the call of duty.

My eternal cheerleaders Rachel Fuller, Ella Hanify, Lisa Harper-Brown, Sarah Hoskyns, Jon Hunter, Catrin Johnsson and Brent Stewart. Thank you for believing in me and encouraging me to always endeavour to improve. Your positivity was a shining light throughout this process.

To my childhood voice teachers, Magdalena Darby and Lesley Graham. Thank you for nurturing my love of performance and supporting me along this journey.

And finally, my incredible family, Mum, Dad, Campbell: you have all endured the hours of practice and late nights. Thank you for always supporting me. I am honoured to have walked this journey with you. Now to sing the finale for this leg of the race. 


\section{Chapter One}

\section{Introduction}

In the 1950s, the so-called 'bel canto revival' signaled renewed interest in operas from the bel canto period and was associated with the emergence of a new generation of singers who had the technical capacity to specialise in the bel canto repertoire. These singers included Maria Callas, Joan Sutherland, and Montserrat Caballé, all of whom gave acclaimed performances of the newly revived repertoire and can be seen as providing expert models of bel canto singing in practice.

At the same time as these singers were being celebrated for their performances of bel canto masterworks, new styles of modern repertoire in English were being developed in Britain and America by composers such as Samuel Barber, Benjamin Britten, Aaron Copland, Lee Hoiby and Gian Carlo Menotti. These operas and art songs were set in the English language and used the text idiomatically, yet they were often intended to be sung in a classical operatic style. By the late twentieth century these songs had become standard repertoire for the modern classical singer.

As a young singer, it is inevitable that one is bombarded with the history of singing. Not only are we asked to listen to vocalists of previous ages, but we are also encouraged to analyse their methods and scrutinise their seminal performances in order to better identify the strengths of each singer. Curious about the extent to which the lauded seventeenth and eighteenth-century bel canto vocal techniques hold relevance to contemporary classical singing and newer compositions, my research focused on whether these well-tried techniques are transferable. While the application of bel canto principles to the bel canto repertoire are clearly pertinent, my investigation concentrated on the feasibility and applicability of transferring these vocal techniques to modern repertoire, specifically songs and arias written in English, my mother tongue. This exegesis details my exploration of the application of such techniques to these two different sets of repertoire, and aims to shed light on the experience of the process of applying 
the bel canto principles to such works, and the potential benefits afforded by the practice of them.

Chapter One will discuss the methodology and exploration of the origins and developments of the bel canto style and principles in relation to predominant treatises of the time. This will serve to articulate my methodology. Chapter Two deals with the definitions and approaches to bel canto principles, defining individual bel canto principles and providing an understanding of their application. Chapter Three delves into my experience of the challenges faced when implementing selected bel canto principles, and also provides information from known singers in regards to placement. Chapter Four takes a closer look at my application of bel canto principles on selected works written to be sung in English. Together this serves to provide an insight into the practical application of the bel canto principles, their transferability for modern day classical singers.

\section{Origins and development of bel canto}

An understanding of the relevance of the bel canto style in its time, provides, I suggest, an insight into the value of the bel canto principles today. Although the written treatises provided by the exponents of bel canto pedagogy of the time provide performers and teachers of today with the tools to craft a bel canto technique, it is important to note, however, that these secondary sources do not clearly provide the information needed to craft a bel canto technique as the treatises are difficult to read in the translated form. Understanding the history and the written treatises outlines the development and the importance of the bel canto principles and those who taught them, providing performers and teachers of today with the tools to craft a bel canto technique. This pedagogic information allowed me to explore the origins and principles of bel canto and implement them in my research process, providing a context that helped my understanding of the bel canto technique. 
Still influential today, the bel canto style of singing originated in Italy during the late sixteenth century and is regarded as having reached its zenith in the nineteenth century. ${ }^{1}$ Although modern writers often use the term bel canto as a label for Italian vocal performance between 1600 and 1850 , the term did not begin to represent a specific style of singing until the second half of the nineteenth century. ${ }^{2}$ What is nowadays called the bel canto technique was developed predominantly by Italian singers and teachers who built on the techniques and perceived perfection of solo singing from late Renaissance polyphony. The bel canto approach was based on a precise control of the voice in an attempt to attain that vocal perfection. ${ }^{3}$

Teachers who influenced the development and application of the technique as it is known today include Pier Tosi (1653-1732), Manuel García II (1805-1906), Giovanni Lamperti (1839-1910), and Mathilde Marchesi (1821-1913). ${ }^{4}$ Realising their importance, scholars and teachers wanting to access the original details today refer to the key documents that were left by these teachers. ${ }^{5}$ These treatises acted as the foundation for my research, providing vocal exercises to form a basis for implementing the bel canto principles.

In addition to the technical application of the term, bel canto was used as a descriptor for a style of composition that came into constant use in the mid-nineteenth century. As the operatic form developed, musicians across Europe of the 1860s noticed a replacement of the old Italian style with an excess of vocal decadence. They longed for the earlier Italian approach to performance which exemplified legato line, focusing on the beauty of the voice. ${ }^{6}$ Over time the term also

\footnotetext{
${ }^{1}$ Rodolfo Celletti and Frederick Fuller. A History of Bel Canto (Oxford, Oxford University Press, 2001) 1-13.

${ }^{2}$ Celletti and Fuller. A History of Bel Canto. 5.

${ }^{3}$ During the Renaissance there were a number of important schools of singing with well-known teachers, among them castrati, developing their technique as they taught and performed. Though bel canto was not yet regarded as a specific technical or theoretical method of singing, its teachers and composers were expert performers and each taught their pupils in the way they had learned, through trial and error, until the students achieved the desired vocal quality.

${ }^{4}$ Manén. The Art of Singing: a Manual of Bel Canto. 11-32.

${ }^{5}$ Pier Francesco Tosi and Gregory Blankenbehler. Observations on the Florid Song: or, Sentiments on the Ancient and Modern Singers. (Pitch Perfect Publishers, 2009) 39. Lamperti. The Technics of Bel Canto. 30-250. Marchesi. Bel Canto: A Theoretical and Practical Vocal Method.

${ }^{6}$ Vocal decadence and excess as discussed in Celletti and Fuller. A History of Bel Canto. 1-14.
} 
came to describe an operatic genre, particularly the works of Vincenzo Bellini (1797-1848), Gioachino Rossini (1792-1868) and Gaetano Donizetti (1797-1848), whose works were the most popular vehicles for the new era of singing, reflecting a return to the earlier Italian bel canto approach of vocal production. ${ }^{7}$ Late nineteenth and twentieth-century sources lead readers to believe that the bel canto technique was restricted to evenness of tone, legato, beauty and expert skill in navigating and performing extremely high florid passages of agility. Indeed, modern understanding of bel canto is a combination of specific vocal principles in order to create what is considered an overall beautiful sound. However, when mastered, the old Italian discipline allowed for complete vocal control; with the principles of sostenuto, coloratura, messa di voce, appoggio, chiaroscuro, voce mista and voce di petto. ${ }^{8}$

Generally, these bel canto principles are considered innately Italian. But with rapidly developing vocal compositional styles in other nations, important changes occurred. As the Romantic movement in music took hold in Europe in the nineteenth century, the audience's hunger for operatic drama evolved. ${ }^{9}$ The Romantic period of Western classical music began in the late eighteenth or early nineteenth century. In this period, music became more programmatic and explicitly expressive with composers focusing on literary, artistic, and philosophical themes, creating gripping storylines for the audience, and often emphasising the text over beauty. ${ }^{10}$ These changes, however, did not affect the fixation on bel canto vocal technique in Italy.

Preferring the bel canto trained singer, late-Romantic composers such as Verdi started writing music that demanded more intense and powerful singing while still holding true to the security of the bel canto principles. This differentiated his music from the compositional changes heard elsewhere in Europe. ${ }^{11}$ These developments are particularly characterized by Verdi's later works, such as Otello (1887) and Falstaff (1893). In the same period, Wagner's revolutionary music dramas appeared, e.g. Tristan und Isolde (1865), The Ring Cycle (1874) and his last composition

\footnotetext{
${ }^{7}$ Celletti and Fuller. A History of Bel Canto. 5.

${ }^{8}$ For more information see Reid. Bel Canto Principles and Practices.

${ }^{9}$ Reid. Bel Canto Principles and Practices. 30.

${ }^{10}$ Manén. The Art of Singing: a Manual of Bel Canto. 19-21.

${ }^{11}$ Richard Miller. On the Art of Singing (New York: Oxford University Press, 2011) xvi-xvii.
} 
Parsifal (1882). This operatic writing demanded a weightier quality of voice, with a requirement for a powerful, speech-inflected style of singing.

While Wagner did not refer to this technique by a specific name, I believe it links directly to the bel canto concept of declamato. ${ }^{12}$ The focus of declamato was to reunite the force of declamation with the gentleness of singing. Declamato is based on the use of a melodic style that is tied closely to the rhythms of the spoken word, moving away from florid ornamentation. Blending the tonal characteristics of the spoken and sung voice, declamato resembled the singers' speech patterns and evoked emotion in the audience through the expression of the text. In training, declamato encourages the singer to utilise the body in speech at pitch and therefore provided a full, connected sound capable of soaring over larger orchestration. Interestingly, both Verdi and Wagner had moved away from the prevailing worship of agility and followed a path pioneered by Christoph Willibald Gluck (1714-1787), which placed an emphasis on dramatic truth. ${ }^{13}$ Wagner strongly believed in the need for vocal training to be based on the principles of the previous century. This is articulated in his 1834 article 'Pasticcio', which lists the technical requirements for good singing: agility, legato and equalization of the registers; with the declamato intention of clearly enunciated text: that the text should be accurately articulated and made totally audible. ${ }^{14}$

While the term bel canto was coined in the 1860 s, and sources lead us to believe that the attributes detailed in the nineteenth century are the only principles associated with bel canto, Stark points to evidence that the use of declamato was an important part of the castrato technique in the sixteenth century. ${ }^{15}$ This strongly suggests that this aspect of singing already existed before Wagner implemented the technique in his operas, further suggesting this principle was part of the

\footnotetext{
${ }^{12}$ Stark. Bel Canto: a History of Vocal Pedagogy. 180.

${ }^{13}$ Neil Howlett, Vocal style in Wagner from the Golden Age to the Present - Lower Male Voices - Neil Howlett. (2015) Neil Howlett. Available at:

http://neilhowlett.com/articles/vocal-style-in-wagner-from-the-golden-age-to-the-present-lower-voices/

${ }^{14}$ Stark. Bel Canto: a History of Vocal Pedagogy. 223.

${ }^{15}$ Stark. Bel Canto: a History of Vocal Pedagogy. 180. A castrato is a type of classical male singing voice equivalent to that of a soprano, mezzo-soprano, or contralto.
} 
bel canto vocal training. ${ }^{16}$ If this aspect of declamato vocal production existed during the bel canto training, it would seem important to use this technique alongside the basic bel canto principles. Taking the Italian principles, the blending of the spoken and sung voice is also relevant in compositions written to be sung in English as the text is expected to be communicated in a conversational manner. ${ }^{17}$ Due to the popularity and influence of these other works, specifically of Wagner and late Verdi, it soon became a compositional development for the Italians to surrender the emphasis on ornate vocalism in favour of the synthesis of word and music. ${ }^{18}$

Philosopher George Bernard Shaw suggested that with the development of the orchestra in terms of its size and the increase in the projection of instruments, the bel canto vocal technique evolved to cope with the extra demands. ${ }^{19}$ The bel canto technique promotes longevity in the voice as the body and the vocal mechanism work simultaneously to create the sound in a sustainable safe manner. ${ }^{20}$ Modern singers today are faced with the challenge of larger, dense orchestras and larger performance venues, paired with the heightened audience expectation influenced by modern media. I believe that this requirement further emphasises the ability of the bel canto principles in assisting with the longevity of the voice.

Bel canto singing technique still has a large following today among opera singers and teachers throughout the Western hemisphere. ${ }^{21}$ Twentieth-century American voice pedagogue Richard Miller was a strong advocate for the bel canto technique, asserting that a singer only needs one technique to accomplish contrasting styles of singing: his works on vocal pedagogy remain influential, particularly in North America. ${ }^{22}$ Though many singers adhere strictly to the principles

\footnotetext{
${ }^{16}$ Anne Rice. A Cry to Heaven: a Novel (Ballantine Books, 2015) 15.

${ }^{17}$ Stark. Bel Canto: a History of Vocal Pedagogy. 31.

${ }^{18}$ Reid. Bel Canto Principles and Practices. 5-12.

${ }^{19}$ Stark. Bel Canto: a History of Vocal Pedagogy. 216-218.

${ }^{20}$ Manén. The Art of Singing: a Manual of Bel Canto. 11-10.

${ }^{21}$ Richard Miller. "A Second Look at National Schools of Singing." National Schools of Singing: English, French, German, and Italian Techniques of Singing Revisited (New York, Scarecrow Press, 2002) xvi-xvii.

${ }^{22}$ Miller. "A Second Look at National Schools of Singing." National Schools of Singing: English, French, German, and Italian Techniques of Singing Revisited. xvi-xvii.
} 
stating that they rely on the old Italian principles to guide them through roles and operas, few point with any detail to specific ways they apply it to nineteenth- century repertoire or modern repertoire. $^{23}$

Due to the rise of verismo operas during the late nineteenth century, the works of Donizetti, Rossini and Bellini started to go out of fashion. Verismo (from the Italian vero, meaning 'true') was a post-Romantic realistic operatic tradition. Verismo was marked by melodramatic scenarios, often featuring violent plots with characters drawn from everyday life. ${ }^{24}$ With the emergence of a new generation of bel canto singers in the 1950s, including Maria Callas, Joan Sutherland and Montserrat Caballé, performers were provided with expert models of bel canto singing in practice, reinforced by their acclaimed performances of the newly revived bel canto repertoire. This interest sparked the so-called 'bel canto revival': a time of renewed interest in not only the technique of bel canto but also the operas of Donizetti, Rossini and Bellini.

The influence of these lauded artists breathed new life into Donizetti, Rossini and Bellini's operas, re-popularizing them throughout Europe and America, and prompted an interest in returning to the old Italian standards. ${ }^{25}$ For every generation it seems there is a 'golden age' of singing. ${ }^{26}$ A phenomenon noted regularly in literature, each 'golden age' usually refers back a generation to excellent singers and a particular way of singing that was an exemplar of its time. Changing vocal demands by the composers of each era would have required the development of new techniques, and this technical development would have taken time to establish, perhaps leading commentators to point to earlier generations as having 'better' technique. However, in the mid-twentieth century, the new examples of bel canto practice provided by the revival

\footnotetext{
${ }^{23}$ Marilyn Horne believes the only way her voice lasted her entire career was from learning and performing with bel canto techniques. Retrieved May 2018 from https:/www.youtube.com/watch?v=XPplK22nSXY YouTube. (2010) Some other artists who identify bel canto as the basis for their technique include Christine Goerke and Thomas Hampson. Donald and Mauro. (2015) 26, 117.

${ }^{24}$ Pietro Mascagni, Francesco Cilea and Giacomo Puccini are composers whose works exemplify the Verismo style of composition which flourished in the last decade of the nineteenth century.

${ }^{25}$ Reid. Bel Canto Principles and Practices. 100-150.

${ }^{26}$ Miller "A Second Look at National Schools of Singing." National Schools of Singing: English, French, German, and Italian Techniques of Singing Revisited. 15-24.
} 
became readily accessible to the current and later generations facilitated by their availability as recordings. Prior to the twentieth-century, singers and teachers worked on the basis of written documents and traditions passed down through generations, and now it is possible to analyse recordings and learn through such recorded examples of 'best practice'. In particular, I am interested in identifying specific aspects of bel canto technique that apply equally to later compositions.

At the same time as Callas, Caballé and Sutherland were reviving interest in nineteenth-century Italian masterworks through their performances and recordings from the 1950s on, new styles of modern repertoire in English were being developed in Britain and America. ${ }^{27}$ Composers including Gian Carlo Menotti, Samuel Barber, Aaron Copland and Benjamin Britten were starting to produce opera and art songs in the English language that used the English text idiomatically, yet were often intended to be sung in a classical operatic style. By the late twentieth century these had become part of the standard repertoire for the modern classical singer, sitting alongside the Italianate vocal music as part of the expected repertoire, at least in English-speaking countries including the United Kingdom, North America, Australia and New Zealand.

\section{Methodology}

My research engaged with a variety of bel canto techniques as described by advocates, practitioners and authors in traditional bel canto repertoire, including Lucie Manén and Manuel

Garcia. ${ }^{28}$ While the term bel canto could be taken to simply imply a well-trained singer, Garcia held that the true nature of bel canto involved specific principles to create an overall beautiful tone throughout a singer's range. I followed their published advice in the form of exercises, applying these principles to selected arias and art songs of the twentieth-century by the American and British composers: Samuel Barber, Benjamin Britten, Aaron Copland, Lee Hoiby and Gian

\footnotetext{
${ }^{27}$ Stark. Bel Canto: a History of Vocal Pedagogy. 186, 223.

${ }^{28}$ Lucie Manén. The Art of Singing: a Manual of Bel Canto. (London: Faber, 1987). Manuel Garcia II. Mémoire sur la voix humaine présenté à l'Académie des Sciences en 1840. (Paris: Duverger, 1847).
} 
Carlo Menotti. I also utilised a self-reflective autoethnographic approach to assist in interpreting the results of my research process.

Initially, I researched the documented descriptions of bel canto techniques, and related these to bel canto revival recordings. Through implementing the bel canto techniques, and using the exercises and approaches described by authors such as Mathilde Marchesi and Giovanni Lamperti, I gained a sense of the bel canto principles in practical terms, and then applied these to both Italian bel canto repertoire and selected modern works, all of which are to be prepared and performed for my Master's recital. ${ }^{29}$

Throughout this process of my practical investigation trialling principles of the bel canto technique, I diarised my experiences and findings in order to effectively communicate my progress and difficulties in interpreting the principles of bel canto. Articulating a diarised account of my practice assisted me in processing my progress and ideas in a structured way. My research displays a personal account of the transference of the bel canto principles onto selected twentieth-century repertoire. These accounts necessarily reflect my own technical efficiencies and deficiencies as a young singing student. Whilst these reflections are personal, they may prove beneficial to multiple readers by presenting the applicability of the bel canto principles and displaying the relevance of utilising these principles on music from different eras, rather than an exclusive focus on applying the bel canto principles to bel canto repertoire.

Critical self-reflection was an essential part of the learning process, especially in learning the repertoire in order to assess the effectuality of transferring these techniques. This was assisted by video and audio recordings during the repertoire learning period to see if the transference of the bel canto principles was successful. For example, listening to recordings of my application of the principle of sostenuto allowed me to gauge whether I was successful in sustaining longer phrases

\footnotetext{
${ }^{29}$ Mathilde Marchesi. Bel Canto: A Theoretical and Practical Vocal Method (New York: Dover, 1970). Giovanni Battista Lamperti. The Technics of Bel Canto. (Pitch Perfect Publishing, 2010).
} 
with a more expressive tone. More on this process can be found in Chapter Four 'Examination of Selected Works.'

I augmented my practical approach through investigation of the following aspects: analysis of musical features in compositions of different eras, analytical evaluation based on my training in diction and language to discern similarities between the Italian language and the English language, with particular attention to vowels and consonants, and, most importantly, the process of implementing bel canto principles in the singing of modern classical compositions of the twentieth-century.

Starting with the acknowledged basic principles of bel canto: appoggio, chiaroscuro, messa di voce and sostenuto, I explored their application in relation to selected arias and composizioni di camera (songs to be performed with piano in the salon) composed by Gaetano Donizetti, Vincenzo Bellini, and Gioachino Rossini. ${ }^{30} \mathrm{I}$ then utilised these principles to my selected arias and art songs of the twentieth century. My aim in learning and applying these techniques was to identify any discrepancies within my vocal technique, to create a more complete foundation, where I am able to sing varying repertoire with consistent beauty of tone. My research will ultimately have a practical and creative application and show that the bel canto principles are transferable to modern repertoire sung in English. ${ }^{31}$

\section{Anglo-Italian Connections: The teaching of bel canto outside of Italy}

Inspiring English singers with their expertise of the bel canto technique, Italian opera stars introduced bel canto to the public in eighteenth century London, making London one of the most

\footnotetext{
${ }^{30}$ More in-depth discussion of these principles will be found later in this exegesis, and further information can be found in James A. Stark, Bel Canto: a History of Vocal Pedagogy, (Canada, University of Toronto Press, 2008).

${ }^{31}$ For more in-depth information on the history of bel canto please see: Celletti and Fuller. A History of Bel Canto. Celletti and Fuller (2001), Stark (2008), Celletti (1991) and Reid (1990).
} 
prominent centres for Italian opera outside of Italy. ${ }^{32}$ Between 1794-1822, the King's Theatre hired many foreign performers, providing London with a diverse musical culture. Famous Italian singers featured included Brigida Banti, Giuditta Pasta and Giuseppina Ronzi de Begnis, who worked closely with Donizetti. $^{33}$ In reaction, pedagogues translated their bel canto treatises into English with specific details on the vocal technique utilised by the inspirational vocalists. Treatises and vocal methods published in England by authors including Mathilde Marchesi, Gasparo Pacchiarotti and Thomas Sheridan in the second and third decades of the nineteenth century show the connection of the vocal principles promoted to those in the eighteenth century. ${ }^{34}$ Marchesi worked and died in England, although she was most prominently known as a teacher based in Paris and counted Dame Nellie Melba and also Muriel Sutherland, Joan Sutherland's mother as her students. ${ }^{35}$ Pacchiarotti also spent most of his life in London and was closely associated with Rossini. $^{36}$ This conveys how the bel canto technique, though Italian, was actively promoted in English, in London. It is interesting to note the Italian connection between the majority of these teachers. This is understandable in a period where many of the teachers and or the singers were either born and trained in the eighteenth century or were trained by instructors whose musical training took place in the eighteenth century in Italy.

Academics and vocal tutors such as Giacomo Gotifredo Ferrari (in 1818) and Garcia (in 1857) finessed their understanding of the bel canto technique through their teaching. ${ }^{37}$ Although compositional styles changed drastically between the late-eighteenth century and the middle of the nineteenth century, most technical principles remained relatively consistent throughout this

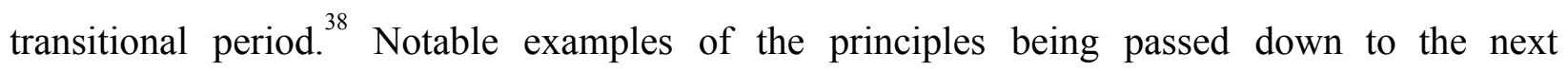
generation include Domenico Corri (1746-1825), who followed the teachings of Nicola Porpora

\footnotetext{
32 The theatre was originally named the Queen's Theatre and was established by playwright and architect John Vanbrugh in 1705. What is today called Her Majesty's Theatre is a West End theatre situated in the City of Westminster, London.

${ }^{33}$ Robert Toft. Bel Canto: a Performer's Guide. (London: Oxford University Press, 2013) 16-18.

34 Toft. Bel Canto: a Performer's Guide. 16-18.

${ }^{35}$ Marchesi. Bel Canto: A Theoretical and Practical Vocal Method. 35-42.

${ }^{36}$ Marchesi. Bel Canto: A Theoretical and Practical Vocal Method. 35-42.

${ }^{37}$ Stark. Bel Canto: a History of Vocal Pedagogy. 3-6, 67.

${ }^{38}$ Celletti and Fuller. A History of Bel Canto. 188-121.
} 
(1686-1768), and communicated Porpora's principles of bel canto to younger generations. ${ }^{39}$ Another is Manuel Garcia (1805-1906), who based his teaching on his father Manuel de Popolo Vincente Rodriguez Garcia's (1755-1832) methodologies. ${ }^{40}$ There is an interesting connection between Garcia II and Rossini. In 1815 Manuel Rodriguez Garcia composed the part of Norfolk for Elisabetta, regina d'Inghilterra and in the following year, Rossini composed the part of Almaviva in Garcia's Il barbiere di Siviglia. ${ }^{41}$

These connections display a clear pattern of interaction between teachers, composers and performers outside of Italy. More recent influential bel canto methodologies include the published methods of Nicola Vaccai (1790 -1848), who composed Romeo and Juliet for the Kings Theatre in 1832 and whose exercises are still taught today. ${ }^{42}$ Giuseppe Concone (1801-1861), wrote exercises to teach bel canto principles which were published in Paris. More connections are evident with Heinrich Panofka (1807-1887), a vocal coach at Her Majesty's Theatre between 1844-1847 and the Victorian opera star and vocal tutor Charles Santley (1834-1922) as well as Mathilde Marchesi. The availability of singers trained in the bel canto style outside of Italy encouraged composers across Europe to develop their composition style, to encompass the Italianate style of vocal composition. ${ }^{43}$ This dissemination of the bel canto principles outside the spheres of Italy and Italian opera is important as it facilitated the access to the teachings and methodologies for English speakers and other nationalities.

\footnotetext{
${ }^{39}$ Toft. Bel Canto: a Performer's Guide. 254.

${ }^{40}$ Stark. Bel Canto: a History of Vocal Pedagogy. 3-6.

${ }^{41}$ Stark. Bel Canto: a History of Vocal Pedagogy. 17-22

${ }^{42}$ Stark. Bel Canto: a History of Vocal Pedagogy. xvii.

${ }^{43}$ It is interesting to note that composers of the time typically composed operatic roles with a singer and their capabilities in mind. The emergence of trained singers and Italian singers headlining outside of Italy gave rise to new compositional possibilities for composers to include in their operas.
} 


\section{Chapter Two}

\section{Definitions and approaches to bel canto principles}

The generally accepted precepts of bel canto have been outlined more recently by writers such as Robert Toft, James Stark and Rodolfo Celletti and include techniques focusing particularly on the ability to achieve a mastery of sostenuto, coloratura, messa di voce, appoggio, chiaroscuro, voce mista and voce di petto. However, the nineteenth century bel canto treatises of Garcia II, Marchesi and Lamperti, as discussed by Celletti in his authoritative text A History of Bel Canto, form the basis for my practical application of the bel canto principles. ${ }^{44}$

In 1840 Garcia II presented the 'steadiness of the voice' as the foundation of good singing, a rare and valuable quality, which he believed was lacking in some singers. ${ }^{45}$ Garcia's 'steadiness' of the voice could be referring to an even tone throughout a singer's range, a tone produced with an even harmonic balance and steady breath flow. Garcia's treatise was written in 1841 (with an additional volume added in 1847), and was only translated into an effective English translation in 1975 and 1984. The volume is a collection of collated versions of the treatise that were edited and translated by Donald V. Paschke. Garcia suggested in his treatise that classical singers of the time were lacking the fundamental principles of good singing, and were disregarding the techniques of previous generations. ${ }^{46}$ It was this realisation and the resounding success of the technique which lead to his championing of the practices of old.

The specific bel canto techniques are: sostenuto: sustaining sounds tied together to create an unending flow of sound, coloratura: training in the skill of executing accurately and elegantly rapid melismatic passages designed to embellish the melodic line. Messa di voce focuses on the ability to begin a note with little colour, and then increase the intensity with a simultaneous

\footnotetext{
${ }^{44}$ Celletti and Fuller. A History of Bel Canto.

${ }^{45}$ Susan Rutherford. "Voices and Singers ." The Cambridge Companion to Opera Studies, by Nicholas Till (Cambridge University Press, 2012) 117-138.

${ }^{46}$ Garcia II. Mémoire sur la voix humaine présenté à l'Académie des Sciences en 1840. 1-11.
} 
deepening of colour. The vocal technique of appoggio stresses the importance of consistent airflow connected to the body throughout all registers of the voice. Chiaroscuro translates to 'light-dark': the combination of a brilliant sound referred to as chiaro or squillo and a dark timbre called oscuro. Voce mista is the mixed voice: mixing the chest and head registers together by using more laryngeal tilt, to allow for the extension of a singer's range upwards, whilst preserving the vocal quality and colour from the lower register. Finally, voce di petto consists of the matching of the voice from the middle register through the chest voice, smoothing the passaggio break and maintaining the harmonic structure of the middle register through the descending passages to the lower register. The Italian term 'passaggio' translates to passage and is used in classical singing tuition to describe the transition between vocal registers.

Underpinning all of these techniques is the mastery of the breath, acting as the very foundation of bel canto technique. There is a very old Italian saying - Chi sa respirare, sa cantare (he who knows how to breathe, knows how to sing). ${ }^{47}$ A simple saying, it encapsulates the importance of the breath: a consistent outflow of air is needed for both sostenuto and messa di voce. Considered the ultimate test for the singer, it required complete control over the vocal mechanism. Messa di voce is a hallmark of bel canto, coming from the Italian mettere (to place), and requires great control in order to create a gradual crescendo and decrescendo on a sustained tone. Richard Miller describes sostenuto as binding one sound to the next. ${ }^{48}$ Furthermore, Laurier Fagnan describes the chiaroscuro principle as the acoustic 'yin-yang of singing,' as a full range of harmonic structure is needed in the vocal sound. ${ }^{49}$ Explanations provide an insight into pedagogic beliefs about the bel canto principles; however, they do not describe how to create these elements in vocal production.

While these requirements for training singers in the bel canto technique seem very proscriptive, I believe every performer is individual, therefore, their vocal training needs to be treated as such.

\footnotetext{
${ }^{47}$ Stark. Bel Canto: a History of Vocal Pedagogy. 91.

${ }^{48}$ Miller. On the Art of Singing. 78.

${ }^{49}$ Laurier Fagnan. The Impact of Bel Canto Principles on Vocal Beauty, Energy and Health Podium 2010 https://www.ualberta.ca/campus-saint-jean/-/media/csj/recherche/bel-canto-vocal-principles.pdf. 3.
} 
Tosi's statement in 1723 in reference to florid singing: "Whoever studies, let him look for what is most excellent, and let him look for it wherever it is, without troubling himself whether it be in the style of fifteen or twenty years ago," encourages today's performers to research and try techniques from past and present vocal pedagogues and performers in order to find what method or methods work for the individual. ${ }^{50}$

\section{Individual Bel Canto Principles}

In the previous section I gave an overview of the bel canto principles of sostenuto, messa di voce, appoggio, chiaroscuro, voce mista and voce di petto. To illustrate their usage, I will now provide some specific details of the way each technical element of bel canto has been described by the various bel canto teachers and writers, and consider ways I have found to interpret them using my own understanding of vocal technique. Although my singing teachers base their teaching philosophy on the Estill Voice Model, they bring into their practice many years of practical experience both in performance and in teaching. ${ }^{51}$ Because of this, my training so far has been a blend of technical and holistic pedagogical ideas that I aimed to showcase in my research. This will be further explored in the examination of my selected works.

As we have seen, multiple vocal treatises stress the importance of creating a stable instrument for performance, stating that performers need to establish a reliable technique in order to create technically consistent performances. ${ }^{52}$ Taking the separate characteristics of bel canto and investigating the implications of such practises, supports such a claim.

A relevant model for the way one might approach this is the model of 'conscious competency,' which is a practical reminder of the necessity to learn new concepts in sequential stages. ${ }^{53} \mathrm{~A}$

\footnotetext{
${ }^{50}$ Tosi and Blankenbehler. Observations on the Florid Song: or, Sentiments on the Ancient and Modern Singers. 39.

${ }^{51}$ Mary McDonald Klimek, et al. Estill Voice Training System, Level One: Figures for Voice Control: Workbook. Estill Voice Training System, 2005. https://www.estillvoice.com/about/

${ }^{52}$ Reid. Bel Canto Principles and Practices. 1-12.

${ }^{53}$ It is difficult to pinpoint the originator of this model. It became current in various forms of business management training during the 1970s, and is described in W.C. Howell and E.A. Fleishman (eds.), Human Performance and Productivity. Vol 2: Information Processing and Decision Making. Hillsdale, NJ: Erlbaum; 1982. Conscious
} 
concern regarding this method of conscious competency is the fear of creating a technical, wooden performance under the misguided assumption that technical training will produce a visibly technical performance. However, pacing the learning of a new skill through sequential stages allows the performer to gently embody the technical concept, to ensure a reliable technical foundation in performance.

\section{Legato / Sostenuto}

The two terms sostenuto and legato could be considered as the same principle as both refer to smooth singing, fusing individual pitches in a musical line. In his methodologies nineteenth-century composer and musical educator John Barnett proposed that the difference lay between the anticipation of the second syllable when two notes where slurred together, with each being set to a separate syllable. ${ }^{54}$ Barnett suggested that to achieve sostenuto the singer should slightly anticipate the second syllable before the beat, in order for intervallic leaps to sound smooth and connected. However, this concept only covers two notes slurred together, not an entire phrase. I have found it more efficient to slightly anticipate every consonant within a word, which allows the vowel to always be placed on the beat. In my opinion, the bel canto principle of sostenuto, like legato singing is not only the connection between each note, but also from vowel to vowel, and consequently, it is essential that the consonant is placed before the beat. Vowels are the building blocks of singing as they are the most open and the most beautiful sounds we can vocally create. The vowels communicate and project emotion to the listener. Whilst the consonants are vital in communicating the text to the listener, it is the vowel which carries the beauty of the line, forming a constant stream of emotive communication. For this reason, I regard the terms of sostenuto and legato as essentially the same principle.

\footnotetext{
competency applies four stages: unconscious incompetence, conscious incompetence, conscious competence, and unconscious competence. This model seemed appropriate when gauging my progress in the implementation of the bel canto principles. My previous study in classical voice performance had provided a general understanding of the bel canto principles leading me directly to Stage Two. Stage Three, conscious competence was reached when I was in the position of implementing the principles into my selected repertoire. Stage Four was attained when the selected principles were implemented without conscious thought.

${ }_{54}$ John Barnett. School for the Voice or the Principles of Singing. (Addison \& Hodson, 1845) 98-102. Barnett had strong connections as a singing-master at Cheltenham, and published the books Systems and Singing-masters (1842) and School for the Voice (1844).
} 
Typically, composers notate their desire for a connected vocal phrase through an extended slur or phrase mark over or under the given notation. Interestingly, Robert Toft comments on the interchangeable nature of the term 'slur' and legato. ${ }^{55}$ This is worth noting as bel canto composers typically apply this notation only over a melismatic passage or a vowel sound spread over multiple notes. The beauty and communicative power of the voice is through the presentation of the vowel, and the presiding concept of bel canto is a legato connected vocal line. The creation of a legato vocal line through the production of the vowels is especially relevant in Romance languages, like French and Italian where the most efficient way of singing is always through the 'pure vowels', which is an Italian concept of resonance, and also purported by voice science as the optimum way of singing. ${ }^{56}$ The vowel is the resonant component of the word, which holds the power to communicate intention and meaning. Whilst consonants are initially expressive, the vowel creates an overall vocal line: some languages like Russian and German are consonant-heavy languages where the consonants act as the individual 'colour' for each language. In my experience, in these cases the consonants need to almost be treated as vowels, singing through the consonant clusters to extend the vocal line.

The principle of legato is fundamental in creating the sense of a harmonically-balanced sound throughout a singer's range, predominantly through producing and maintaining a constant airflow throughout the length of a phrase. In the first edition of Grove's Dictionary of Music, Jenny Lind describes legato singing as an accelerated slur between the intervals, first practiced slowly with exaggerated swooping, then gradually increasing the speed of the slur with "lightning-like rapidity." ${ }^{57}$ This is a skill which must be practiced slowly by the performer in order to maintain a harmonically balanced sound throughout their range with careful attention to the harmonic structure: as a singer descends in their range the harmonic structure must never become distorted. However, the upper harmonics of the sound should increase with each descending note in order

\footnotetext{
${ }^{55}$ Toft. Bel Canto: a Performer's Guide. 58.

${ }^{56}$ Stark. Bel Canto: a History of Vocal Pedagogy. 163-166.

${ }^{57}$ George Grove, and J. A. Fuller-Maitland. Grove's Dictionary of Music and Musicians. 1st ed., General Books, LLC, (2012) 103.
} 
to maintain an overall harmonically balanced sound. The same idea is applicable when singing legato in an ascending phrase, as the lower harmonic resonance should be carried up and maintained on the higher notes.

We know that legato singing is intended to sound like one continuous stream of sound, not as individual, separate notes: this relates to the bel canto school of 'tessitura singing.' Tessitura is the range that a voice type is most comfortable singing in or the range that a piece mostly sits in. In implementing this technique, I found that assessing the phrase as a musical whole, observing the shape of the phrase, the direction, the climax, the beginning and the end aided in creating an overall connected sound. This creates the idea that the musical phrase is considered as one entity, although it is made up of many individual notes, together these single entities make an overall legato phrase.

My research in working with these techniques has established the importance of including my body in the legato conversation, as the body plays a crucial role in stabilising the voice for a musical phrase. According to the Estill Voice Training system it is important to remain engaged in the body in order to stabilise the larynx and support the sound in moving freely. ${ }^{58}$ The back of the neck is important in stabilising the sound; however, my teachers encourage me to ensure that the neck muscles are free and never grip on the individual consonants as this impedes the legato line. ${ }^{59}$

Maintaining a harmonic balance requires consistent vowel placement as well as conscious awareness to the feeling of the sound notated. Shifting the awareness from the sensation to the physiology of the larynx can cause each vowel to have a shifted position and distance the relationship between vowel sounds. Legato sounds require connection through sensation in order to remain harmonically balanced. According to Edmund J. Myers there are no proprioceptive

\footnotetext{
${ }^{58}$ McDonald Klimek, et al. Estill Voice Training System, Level One: Figures for Voice Control: Workbook. Estill Voice Training System. 111-116.

${ }^{59}$ I received this advice in my vocal study with Jenny Wollerman.
} 
nerves which perceive internal larynx movement, only nerve receptors which communicate external movement. ${ }^{60}$ This means that logically there should be no feeling in the larynx, and we can only learn by resonance sensation. ${ }^{61}$ Separating the sensation from the singing can cause a disconnect within a long musical phrase, as the singer moves away from considering the instrument as a whole and focuses on a minute technical level, resulting in a disjointed vocal line made up of individual notes rather than a legato, sustained musical phrase. Training the voice through consistently, consciously training the instrument in the bel canto approach must focus on the sensation of resonance, rather than on the physical movement in the larynx.

In addition to the articulated aspects of bel canto singing, there are other approaches that must be taken into consideration. These extra concepts have provided a great deal of syntactical confusion over the ages, and it is only the development of voice science in recent decades that provides a real understanding of what actually happens.

\section{$\underline{\text { Registers }}$}

In Bernardo Mengozzi's posthumously published treatise he proposed that male voices can sing in either their chest register or their head/falsetto register. ${ }^{62}$ This argument of a voice containing only two registers also applied in his opinion of contraltos and mezzo-sopranos; however, Mengozzi believed that the soprano voice could be separated into three registers. In the final years of the eighteenth century several authors were suggesting a three-register theory for female voices. In his 1792 mémoire Mélopée moderne, Jean Paul Egide Martini described the three female registers as voix de poitrine (chest voice), voix $d u$ gorge (throat voice) for the middle register and voix de tête for what we typically nowadays describe as the 'head voice'. ${ }^{63}$ The terms chest, middle and head are derived from sensations experienced by the singer when

\footnotetext{
${ }^{60}$ Denes Striny. Head First: the Language of the Head Voice: a Concise Study of Learning to Sing in the Head Voice. (Lanham: Hamilton Books, 2007) 57.

${ }^{61}$ Striny. Head First: the Language of the Head Voice: a Concise Study of Learning to Sing in the Head Voice. 57.

${ }^{62}$ Bernardo Mengozzi, et al. Méthode De Chant Du Conservatoire De Musique De Paris En Trois Parties: Première Partie. (Breitkopf \& Haertel, 1893) 36-45.

${ }^{63}$ Stark. Bel Canto: a History of Vocal Pedagogy. 67-69.
} 
producing the different notes associated with the low to high quantification. The lower notes produce sensations in the chest, the middle vibrations may be associated with the throat and highest notes in the register can be associated with the 'mask': the resonating chambers in the face, and may be felt in other parts of the head.

Eighteenth-century vocal pedagogue Ferrari was rather ambiguous with his description and treatment of vocal registers, originally aligning his belief with the three-register method. ${ }^{64}$ Ferrari eventually altered his beliefs in line with Tosi and his two-register theory of voce di petto and voce di testa, suggesting that the weakest of these registers need to be strengthened to match the other. Today's academics and vocal teachers recognise voce di petto as the natural voice, modal voice - in other words the speaking voice originating in the larynx, which can feel like it vibrates and resonates in the singer's chest. Whilst not necessarily appropriate for rapid vocal movement, academics mutually agree on the sonorous, expressive quality of voce di petto. ${ }^{65}$ William Gardiner aptly describes the chest voice as "the most passionate that we utter; they express our innermost feelings, and are termed the language of the heart, as it is from the region of the heart that they sing." "66 Gardiner's comment is intriguing, encouraging me to question whether the location of resonance has an effect on the sincerity experienced by the audience. Perhaps the voce di petto register is associated with the truth as it is typically the closest register to most natural speaking voices. Voices that express the character's truth are forthright in intention and slightly lowered in tone with little inflection, directly associated with the register of voce di petto. ${ }^{67}$ The common problem with vocalists' registers is in creating a seamless transition through the registers throughout the entirety of the singer's range. Mengozzi recommended that the singer sweeten the last note of the chest register and nourish the first note of the head voice in order to match the divide. ${ }^{6}$ Every singer's vocal transition is different, and treatment of the passaggio needs to be treated as such to ensure healthy vocalisation and ease of movement over

\footnotetext{
${ }^{64}$ Toft. Bel Canto: a Performer's Guide. 88.

${ }^{65}$ Further reading: William Gardiner. The Music of Nature. (Cambridge University Press, 1989).

${ }^{66}$ William Gardiner. The Music of Nature. (Cambridge University Press, 1989) 78-105.

${ }^{67}$ This was a premise I was taught as part of speech and drama study with Diane Radford (Wellington, New Zealand).

${ }^{68}$ Mengozzi, et al. Méthode De Chant Du Conservatoire De Musique De Paris En Trois Parties: Première Partie. $36-45$.
} 
the passaggio transition. Typically, there are two points of transition for a singing voice: primo (first) passaggio and the secondo (second) passaggio. The primo passaggio occurs in between the chest and middle registers, while the secondo passaggio lies between the middle and head registers. For most sopranos the primo passaggio is located around ,E-flat' with the secondo typically lying between C-sharp" and F-sharp' (Helmholtz)' ${ }^{69}$

Garcia suggested a definition which fused the two and three register theories together. Through his portamento (where a musician gracefully slides from one pitch to another) exercises, Garcia noticed an overlap between the registers, in which notes over the passaggio could be sung in either register, suggesting the colour of the voice should be considered as one timbre throughout.

${ }^{70}$ Garcia's now famous definition of fused vocal registers is still the touchstone for modern studies in the understanding of register shifts. The nature of this timbre is, however, a controversial issue amongst historians and practitioners. I elaborate on my personal challenges in the blending of my vocal registers in Chapter Three 'Register Challenges.'

\section{Voce di petto and voce mista}

Opera singer and physiotherapist Lucie Manén promulgates the idea that the voce di petto is the register of voice after the 'ugly' break found from singing downwards from the middle register. Manén describes the sound as something singers should avoid when descending in pitch. She also suggests the singer should "raise the centre of the body's gravity" before proceeding down to the break in the voice. ${ }^{72}$ Manén's suggestion is difficult to interpret as it is physically impossible to raise one's centre of gravity. Use of analogy and metaphor is common in vocal training, as music is particularly susceptible to metaphoric conceptualisation as it is subjective, almost invisible and intangible. Metaphors aid performers' comprehension of the complex multidimensional nature of music and music making, especially as singers cannot feel the vocal cords moving. When implementing Manén's suggestion of raising the body's centre of gravity I

\footnotetext{
${ }^{69}$ Miller. On the Art of Singing. 117. Pitch identification using the Helmholtz system.

${ }^{70}$ Stark. Bel Canto: a History of Vocal Pedagogy. 67-72.

${ }^{71}$ Manén. The Art of Singing: a Manual of Bel Canto. 59.

${ }^{72}$ Manén. The Art of Singing: a Manual of Bel Canto. 59.
} 
decided that this metaphor could be promoting the idea of carrying the sound from the upper register down with the descending pitch, connecting the registers to the body, imagining as if the sound and the body is fighting against gravities pull. ${ }^{73}$ The term voce di petto implies that the sound is produced in the chest, whereas there is no difference as to where any note in a singer's range is created, because all notes throughout the singer's range are created through the vocal instrument of the larynx, combined with breath support from the ribs and abdomen. Once again, the vibrations from the pitch are felt in different areas in the body which leads to the misleading categorisations of 'chest' and 'head' voice. Toft suggests that 'chest voice' could also be understood as the 'natural' or modal, voice. ${ }^{74}$ When utilising voce di petto the larynx naturally sinks down into a lower position which requires more retraction of the false folds in order to maintain an open, unconstricted sound, and the lower neck expands. ${ }^{75}$ This warm timbre is comparable to the normal speaking voice (if this positioning is healthy). Healthy speaking consists of a relaxed larynx, freeness in tone, and soft, even vocal fold closure.

Resonance was a prominent concern of Garcia II and is of primary concern of working singers. In the Mémoire sur la voix humaine his definition of timbre was "the peculiar and infinitely variable character which each register, each tone can take." ${ }^{76}$ His main concern was not with the different timbres which characterise individual voices, but with the timbre modifications possible in all singing voices. Garcia focused on two principal types of timbre: clear timbre and sombre timbre. In the Mémoire the timbres were almost treated as registers. Garcia described clear timbre as providing the voice with "lustre" and "brilliance" to the chest register. ${ }^{77} \mathrm{He}$ cited specific cases where singers employed this quality in the chest, among them the famous performance of Gilbert Duprez's high C in Rossini's Guillaume Tell. ${ }^{78}$ According to Garcia, sombre timbre in chest register gives "penetration" and "roundness" to the sound and it makes

\footnotetext{
${ }^{73}$ Manén. The Art of Singing: a Manual of Bel Canto. 59.

${ }^{74}$ Toft. Bel Canto: a Performer's Guide. 88.

${ }^{75}$ McDonald Klimek, et al. Estill Voice Training System, Level One: Figures for Voice Control: Workbook. Estill Voice Training System. 33-40.

${ }^{76}$ Garcia II. Mémoire sur la voix humaine présenté à l'Académie des Sciences en 1840. 1-11xxxv.

${ }^{77}$ Garcia II. Mémoire sur la voix humaine présenté à l'Académie des Sciences en 1840. xxxvii.

${ }^{78}$ Garcia II. Mémoire sur la voix humaine présenté à l'Académie des Sciences en 1840. xxxvii.
} 
the voice capable of more volume, but, used to excess, "covers the sounds, stifles them, makes them muffled and raucous." ${ }^{79}$

From exterior observations of the larynx, Garcia reasoned that the volume differences and contrasting pharyngeal shapes resulted in the laryngeal movements and corresponding movements of the velum, significantly influencing the timbre. He described in detail how the larynx rises as the voice ascends with the scale in clear timbre in all three registers. In sombre timbre, he found the larynx needed to remain fixed, rather low in positioning throughout the scale in chest and falsetto registers, while in the head register it rises rapidly. ${ }^{80}$ In clear timbre, Garcia found the throat to contract between the velum and the larynx, accompanied by a lowered velum and raised larynx creating the clear timbre. For sombre timbre, the throat elongates, caused by a lifting of the velum and lowering of the larynx. Garcia description of sombre timbre was as follows: "the sound is heard full, round and covered; it is what is called mixed voice, or sombre timbre." ${ }^{81}$ This is Garcia's first reference to a mixed voice, describing it as a mixture of timbres rather than of separate registers. This encourages me to consider voce mista as a colour rather than a register, focusing on blending all parts of my voice, ignoring the concept of registers. I believe it is also important to draw attention to a contemporary understanding of voce mista, which uses degrees of laryngeal tilt to blend the vocal registers.

Singers do not receive an accurate aural representation of their vocal efforts live, because although, like the audience, the singer hears the sound waves that travel through the air to their ears, at the same time they also hear the sound waves that travel to their ears through the bones and flesh of their head. This distorts a singer's perception of the sound. Due to this, a singer cannot hear the sound that the audience receives. Nineteenth-century Swedish chemist, inventor, and philanthropist Alfred Nobel believed that "nature was the great teacher and not man." ${ }^{82}$ This quotation is fitting in relation to a performer's practical journey to technical efficiency. As

\footnotetext{
${ }^{79}$ Garcia II. Mémoire sur la voix humaine présenté à l'Académie des Sciences en 1840. xxxvii.

${ }^{80}$ Garcia II. Mémoire sur la voix humaine présenté à l'Académie des Sciences en 1840. xl-xli.

${ }^{81}$ Garcia II. Mémoire sur la voix humaine présenté à l'Académie des Sciences en 1840. xliv.

${ }^{82}$ Striny. Head First: the Language of the Head Voice: a Concise Study of Learning to Sing in the Head Voice. 76.
} 
well-known vocal pedagogue and bel canto expert Cornelius L. Reid stated, vocal production can become forced when an individual bases their teaching upon their own ideas of the voice. ${ }^{83}$ Nobel implies that the technique of good singing already lies within the singer and as teachers and performers we just need to nurture the sensation, rather than manoeuvre the larynx to manufacture the sound. This concept shifts focus away from trusting the sensation of the voice and creating a sound through the scientific understanding of the physiology in the throat. Singer and author Denes Striny suggests this misdirected focus away from sensation stemmed from Manuel Garcia's invention of the laryngoscope, which provided more information on the working mechanics of the larynx. ${ }^{84}$ According to the bel canto teachers, voce di petto and voce mista should not be considered as separate entities in order to ensure a consistent tone throughout a performers range. I found this a helpful concept, as I focused on creating an even, harmonically balanced tone throughout my vocal range, matching one note to the next. This allowed me to match every note, rather than altering the tone in specific registers in an attempt to make them match.

\section{Breathing and appoggio}

The appropriate manner of breathing is a hotly-contested subject by singers and coaches around the world. Understandably so, as the management of the breath is vital for vocal production. However, the earliest theoretical writings treat this subject with almost complete indifference. One of the founders of our contemporary idea of opera, Giulio Romolo Caccini (1551-1618), merely mentions the control of the breath in a 'casual' way, suggesting that a human already knows how to breathe, and that therefore, a singer should breathe in the same manner as they do in everyday life. ${ }^{85}$ This simplistic approach was also mimicked by Italian composer and bel canto singing teacher Ferrari in his Concise Treatise on Italian Singing, where he simply stated "the inspiration should be made at the beginning and at the end of the musical phrase."

\footnotetext{
${ }^{83}$ Reid. Bel Canto Principles and Practices. 18-33.

${ }^{84}$ Reid. Bel Canto Principles and Practices. 5-12.

${ }^{85}$ Giulio Caccini. Le Nuove Musiche: Firenze, 1601 (Recte 1602), 1614, Venezia, 1607, 1615. Cornetto, Gedruckt in Lizenz Von Musedita, (2006.)

${ }^{86}$ Stark. Bel Canto: a History of Vocal Pedagogy. 67-69.
} 


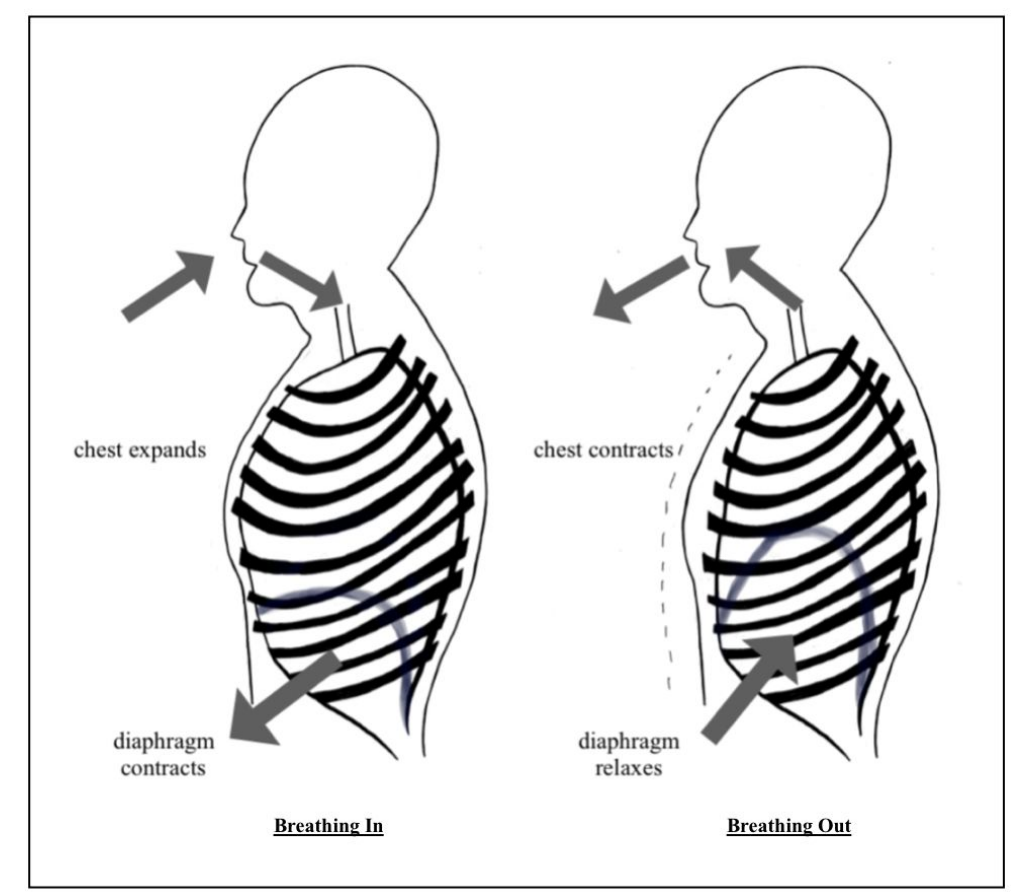

Diagram representing the action of the diaphragm when breathing

Amongst other attributes, bel canto singing relies on a steady management of the breath to assist in sustaining the long, virtuosic phrases. The primary function of the breath when singing is to create and support vocal tone: therefore effective breath control is an efficient mechanism, where little demand is placed on the breath, as all energy is directed to constructive channels where the breath is not wasted, for example, on exaggerated consonants. There are a number of different 'styles' of breathing each with their own followers. High chest cavity breathing involves the inhaling of minimal breath into the lungs, by drawing air into the chest area using the intercostal muscles of the upper ribs, rather than by means of the movement of lower ribs and/or the diaphragm. This 'high' breathing style, which restricts the amount of air taken in, is a typical response for beginner singers who mismanage their breath and breathe in a shallow manner, ultimately restricting their ability to sustain longer phrases. On the other hand, English baritone and voice teacher Colin Baldy suggests that diaphragmatic breathing allows the vocal cords freedom to vibrate without obstructing the movement of the glottis (the part of the larynx 
consisting of the vocal cords and the opening between them). ${ }^{87}$ This breathing method is similar to the natural breathing that the body uses 'at rest' such as when sleeping, where the body inhales, taking the breath into the lower area of the lungs and the abdominal space. ${ }^{88}$ The chest remains relatively passive during this action, however, the stomach will usually protrude slightly, naturally, with each inspiration due to the chain reaction of the lower abdominal muscles releasing. The efficiency of the vocal mechanism is determined by the natural speed and rate of breath expulsion. ${ }^{89}$ During speaking and singing the breath is regulated by the voluntary nervous system, contrasting to the involuntary nervous system operating in our natural state. When performing an extended musical phrase, the singer's voluntary control of the breath quashes the natural involuntary pattern of breathing. On a singer's inhalation the diaphragm flattens and lowers as the external intercostal muscles lift and spread the ribcage; on exhalation, the diaphragm rises as the internal intercostal muscles pull down and compress. The understanding of the physiological process of breathing aided in my understanding and implementation of the bel canto principle of appoggio.

Appoggio is a breathing technique which is highly dependent on bodily posture and the interaction of the different muscles used for singing. The word appoggiare means to lean against, to be in contact with, to support. In appoggio technique, the chest and sternum remain relatively stationary, neither rising or falling, starting and maintaining in a noble posture with the head, neck and torso in alignment. Importantly, the ambition is for the ribs to remain virtually in the position they were placed in after inhalation. During inhalation, there will be expansion felt in the lower rib cage and on the front and sides of the lower torso. The lateral abdominal expansion should equal, or even exceed, the forward expansion. The main point of the appoggio breath-management system is to remain in the position of inspiration for as long as possible. It is a support system that holds in balance the muscles engaged during inhalation and exhalation, and also the muscles of the larynx. The goal is to allow the abdominal wall muscles to control the

\footnotetext{
${ }^{87}$ Colin Baldy. The Student Voice: an Introduction to Developing the Singing Voice. (Edinburgh: Dunedin Academic Press, 2010) 18-23.

${ }^{88}$ Baldy. The Student Voice: an Introduction to Developing the Singing Voice. 18-23..

${ }^{89}$ Stark. Bel Canto: a History of Vocal Pedagogy. 253-257.
} 
airflow of exiting air, not letting it out too quickly, while making sure that the larynx remains steady or even slightly lowered.

Appropriate breath management involves using the entire body to create a stable platform for the breath to move freely. In addition, the control of the breath needs to remain adaptable in order to adjust to the vocal demands required by the performer, and were essential to my research into the viability of the transference of these techniques to twentieth-century repertoire. 


\section{Chapter Three}

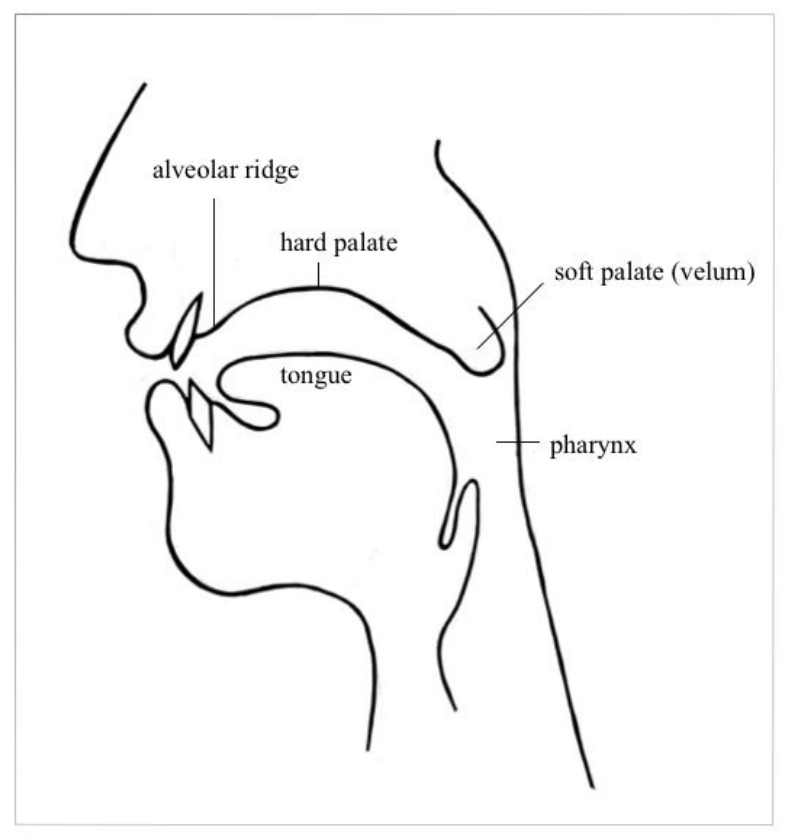

Diagram depicting the alveolar ridge, pharynx, hard and soft palate.

\section{Thoughts on vocal 'placement' from well-known singers}

It is interesting to consider what some great bel canto singers have said about the placement of their voice. 'Placement' is an aspect of vocal production referred to by proponents of bel canto and it is mentioned by Celletti as an important part of the bel canto technique. The singers below all championed the bel canto revival, acting as an exemplar for their generation and the following generations of classical singers. ${ }^{90}$ These singers were all utilising the bel canto principles in performance, and so it can be assumed that what they were experiencing in respect to resonance (while an individual sensation) is of tremendous importance to any researcher of the principles of bel canto. The following remarks regarding vocal placement provides an insight into the sensation experienced whilst performing with the bel canto principles. This may be one of the few sources that provides me with a consistent insight into the sensations needed for correct bel canto placement.

\footnotetext{
${ }^{90}$ Jerome Hines. Great Singers on Great Singing (Wisconsin: Limelight, 2006) 32-45.
} 
Famous Italian tenor Franco Corelli (1921-2003) suggested that "if you feel the voice striking in the mask, you know that the voice and throat are free." ${ }^{91}$ Corelli is referring to feeling the vocal resonance in the face as if wearing a mask, implying that if a sound is felt forward in the face it is a free sound. Similarly, American mezzo-soprano Marilyn Horne (b. 1934) also described the mask resonance sensations "I feel my whole concentration is coming out here in front...in the mask." New York-based American operatic soprano Rosa Ponselle (1897-1981) also used the analogy of mask resonance when describing her vocal production "You use the mask for placement." In Internationally renowned bel canto tenor Luciano Pavarotti (1935-2007) described his harmonic placement in regards to his vocal registers as consistently high, in order to ensure that he maintained brightness when singing lower pitches; "For me the position is always high...even when I sing low notes." "J4 Joan Sutherland (1926-2010) was an Australian-born coloratura soprano who stated in an interview "one feels as if the sound were being projected against the front of the hard palate." ${ }^{95}$ Finally, Swedish dramatic soprano Birgit Nilsson (1918-2005) reiterates the imagined placement of placing the vocal sound in the mask; "I try to place the voice as far in front as possible...in the mask...without getting nasal. When I feel that the voice just bangs in the head, then I know it is in place." ${ }^{96}$

The singers are not describing their placement of the voice in their larynx or throat. Each outlines a sensation placed in the head, describing a secondary resonance created by the vibration of the bones in the head. The singer's formant is thought to be associated with one or more of the higher resonances of the vocal tract, aiding the opera singer by assisting them to be heard over an orchestral accompaniment. Studies of the frequency spectrum of trained singers, especially male singers, indicate a clear formant between 2800 and 3400 Hertz that is absent in speech or in the spectra of untrained singers. ${ }^{97}$ This is important to note as each of the above singers use

\footnotetext{
${ }^{91}$ Striny. Head First: the Language of the Head Voice: a Concise Study of Learning to Sing in the Head Voice. 55.

${ }^{92}$ Striny. Head First: the Language of the Head Voice: a Concise Study of Learning to Sing in the Head Voice. 55.

${ }^{93}$ Striny. Head First: the Language of the Head Voice: a Concise Study of Learning to Sing in the Head Voice. 55.

${ }^{94}$ Striny. Head First: the Language of the Head Voice: a Concise Study of Learning to Sing in the Head Voice. 55.

${ }^{95}$ Striny. Head First: the Language of the Head Voice: a Concise Study of Learning to Sing in the Head Voice. 55.

${ }^{96}$ Striny. Head First: the Language of the Head Voice: a Concise Study of Learning to Sing in the Head Voice. 56.

${ }_{97}$ Striny. Head First: the Language of the Head Voice: a Concise Study of Learning to Sing in the Head Voice. $76-81$.
} 
individual analogy and metaphor to describe a sensation placed in the body, not once describing the physiology required to make the sound. In attempting to create the desired bel canto sound, I aimed to recreate the described sensation of resonance, focusing my attention on striking the sound in my mask resonators (using the upper resonators, aiming the sound in the front of the face). This encouraged me to keep the placement forward to ensure a bright, clear tone colour. I believe this is what the above singers were all referring to, using bodily metaphors to describe the ringing sensation felt in the head when applying bel canto principles in the correct manner.

Control of muscles cannot be accomplished by merely reading music in the moment, or by a theoretical understanding. This control must always be learned by the repeated action of doing, physically repeating an action over and over, building muscle memory. An integral component of performance is practice, as the effort applied in the practice room directly enhances the live performance. New understanding cannot be absorbed into the body instantly, the process takes weeks, months if not years of practice. Perfect practice is necessary for mastery.

\section{Practice does not make perfect - it makes permanent}

- Alexander Libermann ${ }^{98}$

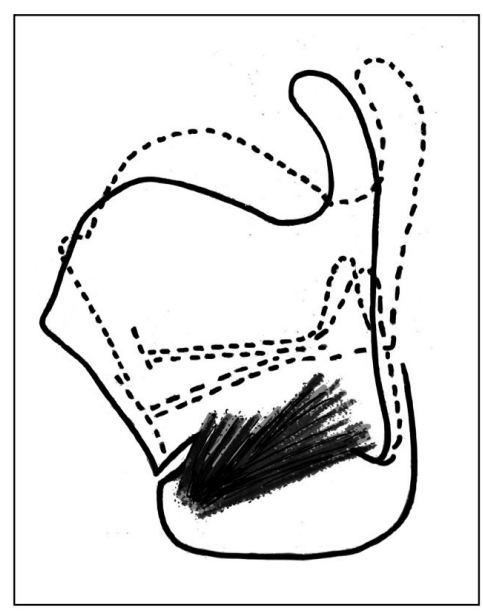

Diagram representing the larynx in a 'tilted' position.

${ }^{98}$ Alexander Libermann. "How to Practice." How To Practice, howtopractice.com/music-practice-quotes. (2000) 


\section{Register Challenges}

Throughout my research process, practice was crucial in fine tuning the bel canto principles. Slow, deliberate practice aided in determining which principles would assist my technical deficiencies and finesse my performance style.

A problem I have faced throughout my vocal training is the blending of vocal registers. My voice has been described as schizophrenic, suggesting I possess many voices, all different, none relating to each other. I have always been told that the top register of my voice is free and easy showcasing a free resonant ring as I keep the sound supported and do not force my air pressure. The bottom of my range has a strong earthy quality, quite separate from the bright resonance of my upper range. The middle section of my voice occasionally lacks support, and I struggle with the transition to my upper register moving over A' to E" (Helmholtz). First, I experimented with Mengozzi's recommendation of sweetening the last note of the chest register and nourishing the first note of the head voice in order to match the divide. I struggled with the concept of 'sweetening' the sound as this suggests a change of timbre. This added to my confusion as it almost suggests creating another sound entirely. Sweetening the last note could also relate to transitioning slightly earlier into the colour associated with the upper register. My voice teachers have taught me that in order to keep even partial balance for full resonance the velum (soft palate) must remain in a raised position. The levator veli palatini is the elevator muscle of the soft palate. This muscle must remain engaged during the passaggio shift with optimum laryngeal tilt. Laryngeal tilt automatically creates a 'sweeter' sound as the tilted position naturally creates a natural free vibrato in the sound.

I found through experimentation that an exercise which assisted this raised palate vocal position was breathing in nasally. The in-breath through the nose before singing the phrase crossing from middle to the upper register created a stable position before crossing over the passaggio. This preparation created a smoother transition. Another important contributing factor to a smooth passaggio transition is support (stabilisation) of the head and neck. When approaching the upper 
register the muscles that close around the velopharyngeal port tighten. ${ }^{99}$ I found that concentrating on engaging support and focusing on sensations above the palate and in the centre of the head helped me to feel as if the sound was already positioned in the upper register.

Another problem I have encountered whilst trying to match my registers is constriction. Constriction is when you create vocal sound with excessive tension in the throat. Constriction of the throat is obvious when a person lifts something heavy, as it prevents a strain on the vocal folds because the 'constrictor muscles' that shape the vocal tract protect the vocal folds. However, uncontrolled constriction can impact the vocal folds ability to stretch. ${ }^{10}$ Supporting the voice using muscles in the neck is important, however, it is the uncontrolled constriction which becomes the singer's enemy, not exactly the muscles themselves. Without constriction it is easy for the vocal folds to stretch and slacken: this action only becomes cumbersome and difficult when the action is obstructed. The obstruction of this movement via constriction can make the quality of the tone produced by the singer sound compressed, disturbing the balance of the partials in the sound. This uncontrolled constriction can also make navigating the passaggio difficult, making higher notes in the register harder to reach. I have observed in other performers that typically a singer will try harder to reach the top notes, often worsening the uncontrolled constriction. Eventually, under this tension the vocal folds will struggle to stretch. The reason why the high notes are unsuccessful is not due to a lack of vocal ability, but the uncontrolled constriction around the vocal folds, robbing the vocal fold of the necessary space required for them to stretch for the higher notes in the singer's register. This is needed so the folds can vibrate freely and the larynx can move freely to create the necessary laryngeal tilt.

In classical vocal instruction a common suggestion regarding avoidance of constriction is 'to keep an open throat.' Whilst it is not possible to physically 'open' the throat, it is possible to avoid constriction by imagining the sensation of an open channel from the breath supply to the lips. My voice teachers have suggested that a singer can widen the upper throat by loosening the

\footnotetext{
${ }^{99}$ McDonald Klimek, et al. Estill Voice Training System. Workbook, Level Two. Estill Voice Training Systems International. 53-63.

${ }^{100}$ McDonald Klimek, et al. Estill Voice Training System. Workbook, Level Two. Estill Voice Training Systems International. 60.
} 
middle constrictor and raising and widening the fauces (the arched opening at the back of the mouth leading to the pharynx.) ${ }^{101}$ Throughout my research process this open sensation assisted in keeping the soft palate raised and helped in encouraging the muscles in the neck to not over-engage. I have realised the importance in being able to feel the difference between a constricted sound and a well-managed free sound. Understanding the difference in sensation should help the performer's awareness when practising towards creating a free, unrestricted sound. A constricted sound can be actively produced by the performer to understand the incorrect technique. I find that pushing the abdominals outwards and bending the torso a little, helps in exaggerating the tight feeling in the larynx. Singing a phrase over the passaggio with constriction and then immediately remedying the situation, performing with a free sound, clearly distinguishes the incorrect technique from the correct technique. Constriction is also directly related to an increase of air pressure below the larynx. This places an unworkable amount of pressure on the vocal folds, making it incredibly difficult for the vocal folds to move freely also making the singer fatigue earlier. When the constriction is under control the stretching of the vocal folds is unhindered, ensuring secure pitch, and reduces wear or fatigue of the vocal folds.

Throughout my research process I battled with constriction in multiple situations. I found that the consonant heavy nature of the English language almost seemed to encourages me to over-enunciate the text in an attempt to be understood. The strain over the consonants in the English text then transpired onto the vowels as well as on the consonants. Maintaining full false vocal fold retraction in a giggle position, imagining the sensation of the space in the throat widening, assisted in creating a free sound. This is the method I utilise when singing Italian bel canto repertoire, so naturally this assisted in maintaining the integrity of the English vowels. There are multiple positions for the false vocal folds during voicing: the closing detected in straining, the mid-range position associated with the spoken voice, and the open sensation related with the activity of laughing. The muscles that close the true and false vocal folds operate in the manner of a sphincter muscle, and are thought to be mainly intrinsic. The position of retraction is associated with giggling as it mimics the open position of laughter where the false vocal folds are

\footnotetext{
${ }^{101}$ I received this information from vocal study with Margaret Medlyn.
} 
moved outwards from the middle position to a wide, open position. I implemented this technique gradually and practiced the open position over my entire range, with particular focus over the passaggi. This allowed me to gently apply the vocal positioning used in my Italian bel canto repertoire to my performance of songs written to be sung in English. Throughout the process of my research I discovered that the way in which I practised, is the way in which I performed. I concluded that relaxed control of the vocal mechanism and breath in the practice room results in a relaxed representation of the effort in live performance, minimising the possibility of constriction. Once I felt that I was in control of matching my vocal registers, I turned my attention to the chiaroscuro bel canto principle.

When practicing the troublesome phrases on a fricative [v] I noticed my lack of breath control and the excess breath around my sound when reverting back to the original text. A solution suggested by Dame Malvina Major and Estill voice training towards removing the excess breath causing constriction, is to exhale the excess air in order to take a recoil breath. Dame Malvina suggested to me in a coaching session that I should purposefully release the respiratory muscles after singing a phrase, instead of actively inhaling. This will demonstrate the amount of air which was used, and the amount of air that was held back due to the vocal constriction. After identifying the moments where I was constricting over my passaggio and once the air pressure has been established, using the extended consonant[s] assisted in appropriately pacing the air flow in a relaxed manner. I repeated this action multiple times successively to build in an intrinsic understanding of the relaxed breath required for the specific phrase. After approximately five repeats I paused, revisiting the musical notation for the specific phrase, actively distracting my mind. Repeating this action after a pause reveals whether that habit has been successfully ingrained. I believe that once the habit has been established it would be appropriate to graduate to a vowel stream and eventually the text. Every phrase needs to be planned with appropriate breath management which is always produced in an engaged, yet relaxed manner. It is crucial to rehearse the breathing in a relaxed manner as extra tension could encourage constriction. 


\section{Chiaroscuro in Practice}

When discussing tone colour in the singing voice, the term used to describe the dynamic light and shade is chiaroscuro, quite literally light-dark in Italian. The term first appeared as a description of painting and drawing techniques in the fifteenth and sixteenth century, referring to clear tonal contrasts which are often used to suggest the volume and modelling of the subjects depicted. ${ }^{102}$ The principle of chiaroscuro in classical singing was not formed by one particular vocal theorist, rather, chiaroscuro was developed in stages over an extended period of time, as vocal theorists gradually transformed their tonal preference of a classical singer into pedagogical concepts. ${ }^{103}$ It was during the eighteenth and nineteenth centuries that the ideal vocal quality of a 'bright-dark' (chiaroscuro) tone evolved, and the principle became a crucial component of the bel canto singer's technique. ${ }^{104}$ The expectation was that every note sung should have a bright cutting edge, balanced by a dark round quality, forming a complex texture of resonances. The earliest documentation of this term in relation to classical singing was in 1774 in Giambattista Mancini's Pensieri e riflessioni pratiche sopra il canto figurato, which was later translated into German, French and English. ${ }^{105}$ Mancini created a methodology to implement chiaroscuro into the singer's vocal technique. His instruction was for the singer to practice slow scales, suggesting that this exercise would make any singer a master of colouring the voice.

I implemented Mancini's method by singing scales beginning in my lower register, gradually moving higher. This assisted in carrying up the darker quality to my upper register, where the voice can become squashed and sometimes shrill. Slow, dedicated practice also encouraged me to match each degree of the scale to the last, hopefully assisting in creating the light and dark resonances required for the desired chiaroscuro sound. Mastery of this principle generates interest in the vocal timbre, whilst also establishing a matched sound throughout my range, important for repertoire sung in both Italian and English.

\footnotetext{
102 Stark. Bel Canto: a History of Vocal Pedagogy. 33-56.

103 Stark. Bel Canto: a History of Vocal Pedagogy. 33-56.

104 Stark. Bel Canto: a History of Vocal Pedagogy. 33-56.

${ }^{105}$ Giambattista Mancini. Pensieri, e Riflessioni Pratiche Sopra Il Canto Figurato (Italy: Stamparia Di Ghelen, 1774).
} 
One of the most famous teachers of the nineteenth century, Lamperti, maintained that no matter how wide a singer's range, it was crucial for the chiaroscuro to always be present, reinforcing how important the principle of chiaroscuro is in crafting a bel canto voice. ${ }^{106}$ Garcia II pioneered the explanation of quality as a systematic process, most pertinently making clear distinctions between the effects of the glottal mechanism and the effects of the resonance tube (throat and mouth) in singing. Garcia II believed in establishing firm glottal closure to create the ringing quality in the voice, suggesting the weak or loose glottal pressure would result in a 'veiled' sound, muffling and distorting the bright resonance and 'ping' desired. ${ }^{107}$ He also suggested that the vocal darkness could only be crafted by the positioning of the vocal tract. The shape of the vocal tract (which includes the mouth) is changed by the movements of the tongue and the lips. This, coordinated with degrees of glottal closure, and the vertical positioning of the larynx, produces the colours in the voice, and is what Garcia called 'the tints of the voice. ${ }^{108}$ The Estill Voice Training system has taken this further, by categorising different sounds or 'qualities' of the voice, by the different shapes and positions of the vocal tract and larynx. In bel canto singing, chiaroscuro has long been considered the ideal vocal quality. ${ }^{109}$ The combination of the bright 'ping' and the dark roundness creates expressive colours associated with the old Italian school of singing, relevant in past centuries and still relevant for modern-day classical singers.

When practicing this technique I became confused with the opposing elements of bright and dark, often possessing too much brightness in the top of my range, and indulging in the darkness of timbre in the bottom of my range. I found that Mancini's scalic method allowed me to focus on connecting my timbre throughout my range. The notion of 'connecting' the timbre together, mirrors the connection required in the body to maintain false vocal fold retraction whilst moving upward. This ensures that the heaviness and thickness of the vocal folds is not dragged up, only the colour of the timbre. The false vocal folds are situated above the true vocal folds and are used for actions like swallowing and coughing. Connecting with my body allowed me to ground myself in my stance, a constant reminder to anchor the larynx in the slightly lowered position in

\footnotetext{
${ }^{106}$ Lamperti. The Technics of Bel Canto. 30-250.

107 Stark. Bel Canto: a History of Vocal Pedagogy. 11-27.

108 Stark. Bel Canto: a History of Vocal Pedagogy. 38.

${ }^{109}$ Stark. Bel Canto: a History of Vocal Pedagogy. 56.
} 
order to achieve the dark quality of chiaroscuro. This stabilisation created a consistent instrument throughout my scalic practice, crucial in creating a consistent timbre possessing both light and shade. To aid in the consistent implementation of the principle of chiaroscuro, I associate the darkness with a lowered laryngeal position anchored by my stance and forward mask resonance placement to create the bright ping of the light component of chiaroscuro.

\section{Vowels and Diphthongs in the English Language}

Bel canto repertoire was predominantly written and performed in the Italian language. This is important to consider when applying the bel canto principles to repertoire written to be sung in English: English is an incredibly difficult language both to speak and sing. ${ }^{110}$ The abundance of diphthongs (words where one syllable contains two vowel sounds) and triphthongs (words where one syllable contains three vowel sounds) make it incredibly easy to distort the core quality of the pure vowels, further distorting the overall musical line. Many great composers of the twentieth century composed in English. A common assumption is that singers are always at their best when they are articulating in their native tongue. ${ }^{111}$ This supposition may be correct in regards to an actor's performance, however, a native English speaker's sung performance is usually fraught with diction issues. Firstly, one of the biggest habits of native English speakers is placing undue stress on unstressed schwas [ə] vowel. ${ }^{112}$ A schwa is a neutral vowel used to neutralise speech, countering the pure vowels and preventing over-pronunciation. To sing a schwa accurately; however, a singer must be able to sing on this neutral vowel. This completely distorts the word and hinders the musical line. An example in Barber's song 'Nature the gentlest mother' is the first sung word, 'nature.' The secondary syllable 'ture' involves a schwa vowel, and falls on an unstressed beat, within the descending interval of the word. This descending interval makes it easy to stress the schwa, distorting the stress value of the word, when the stress is intended to fall of the first syllable of 'na.'

\footnotetext{
${ }^{110}$ Rupert Christiansen. Singing in English: It's harder than you think. (Telegraph.co.uk, 2013). https://www.telegraph.co.uk/culture/music/opera/10053327/Singing-in-English-Its-harder-than-you-think.html ${ }^{111}$ Christiansen. Singing in English: It's harder than you think. https://www.telegraph.co.uk/culture/music/opera/10053327/Singing-in-English-Its-harder-than-you-think.html

${ }^{112}$ For ease of pronunciation description I have utilised the International Phonetic Alphabet (IPA).
} 
By contrast, the Italian language contains only pure vowels, making pronunciation easier when crafting the vocal line. I found when practicing the bel canto repertoire of Bellini, Donizetti and Rossini that the Italian language assisted the Italianate requirements of a legato line and evenness of tone. This is understandable considering the origins of bel canto, as the principle of legato relies on the vowels and consonants. I had previously discovered that when preparing my Italian bel canto repertoire, speaking the text aloud enabled me to compare and correct my vowel formation and clearly focus on appropriate word stress, alerting the singer to where the appropriate stresses of the word and sentence lie. This holds true for repertoire to be sung in both the Italian and the English language. Reverting back to this technique for English would create a clear syllable stress map for the singer to follow. I decided to use the technique of learning a foreign language when singing in English despite it being my native tongue, to force me to return to basics.

In the English language, the schwa vowel is found in every possible position within a word, particularly in the unstressed syllable of a multisyllabic word. The mouth opening for the schwa is similar to the short $[\mathrm{u}]$ vowel but smaller. The position is created with neutral lips, paired with the centre of the tongue placed centrally in the mouth. To add to the difficulties, the schwa vowel may be spelled in innumerable ways. This vowel can be altered to correlate with the stressed vowel within the multisyllabic word. This alteration helps to maintain a consistent resonance space within the word, making matching the harmonic partials over a phrase easier. I found that this technique must be delicately practiced in order to ensure the integrity of the neutral vowel is still recognisable.

Some examples of the schwa in multisyllabic words are:

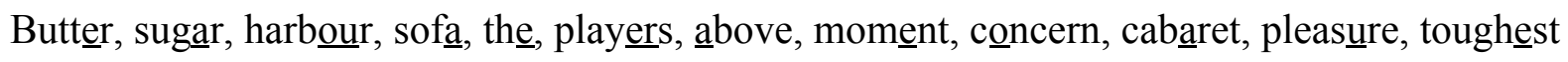

Every singer has a preferred vowel to vocalise on, which in a trained voice displays the ideal placement for vocal resonance. When this resonant placement is transferred to all vowels, it ensures a matched tone throughout. When asked in an interview to describe what made him 
great, Luciano Pavarotti said that every day for two years his teacher made him practise placing all the vowels in the same space and sensation as the closed Italian $[\mathrm{u}]$ vowel. ${ }^{113}$ When he finally accomplished this successfully, only then did he feel that his voice was completely matched. ${ }^{114}$

Vowel sounds are formed by the vocal tract being moulded into different shapes by the speech organs. The vibrations (sound waves) then have different ranges on the harmonic spectrum emphasised as formants because of this change of shape. Resonance is carried on the vowel, acting as a crucial component of emotional expression in sung performance. Speech relies on vowel sounds for understanding, projection and for creating an effect on the audience. The way in which we speak heavily affects how we sing, as the majority of individuals speak more than they sing. This sad fact for a singer can result in embedded bad habits transferring from speech into the pure vowel production for singing. As a native English speaker, I do not specifically think of the individual vowels before I sing them, in contrast to my preparation of the Italian language in bel canto repertoire where every vowel is considered before voicing. Bel canto treatises state that the Italianate vowels in vocal production need to be pure and consistent, it is crucial for the vowels to match throughout the entirety of the vocal production. ${ }^{115}$

When singing I carefully plan my vowels and their relationships with each other to ensure consistent vowel matching throughout. I write this analysis above my musical score with the International Phonetic Alphabet (IPA). Before completing this research when singing English, I typically only ever reminded myself of double consonants or consonants which needed stressing. Transferring my preparation of the Italian language used in my bel canto repertoire over to my preparation of repertoire sung in English dramatically changed my vowel production. Above the English libretto I wrote out the IPA for the vowels and consonants, deciphering the diphthongs

\footnotetext{
${ }^{113}$ Mark Hoeler. Luciano Pavarotti Speaks about Concentration, Diaphragm, Throat, Resonance. 2016. www.youtube.com/watch? $=0$ gp35OUFBlk.

${ }^{114}$ Hoeler. Luciano Pavarotti Speaks about Concentration, Diaphragm, Throat, Resonance. www.youtube.com/watch? $=0$ gp 35OUFBlk.

${ }^{115}$ Mengozzi. Méthode De Chant Du Conservatoire De Musique De Paris En Trois Parties: Première Partie.
} 
and triphthongs to ensure the vowels were accurate and consistent. This analysis encouraged me to become overtly aware of the vowels sung in English. Clearly seeing the pure vowels above the text not only assisted in correct pronunciation, but also assisted in my ambition of applying the bel canto principle of legato.

Given this finding, I have concluded that a constructive exercise to assist in understanding the neutral schwa vowel would be to write the IPA over the entire libretto of the piece, clearly identifying the schwa vowels even when singing in your native language. Practicing the vowels in isolation in relation to the word it is situated in, will aid in creating consistent resonant placement for every schwa vowel. This deliberate practice will also support understandable pronunciation, and help in forming appropriate stress patterns in multisyllabic words in line with transferring the bel canto principles to modern repertoire written to be sung in English.

\section{Diphthongs}

A diphthong is two consecutive vowel sounds within a word, contained in one syllable. Spoken English in New Zealand and some other countries exaggerate and elongate these separate vowel sounds, placing excessive stress on the individual vowels, almost distorting the integrity of the vowel. The aim behind the action of a diphthong, is a continuous glide between the two sounds, with a gradual and continuous movement of the speech organs. The closing end of the diphthong in English typically moves from a more open position to a closed position. When speaking a diphthong, the closing action is typically created by the jaw moving from an open position, closing to a smaller position. This is extremely dangerous when singing, as closing the jaw distorts the resonant chamber of the mouth. Closing the jaw without due attention to the space in the oral cavity can also pull down the soft palate, squashing the harmonic partial balance. I have noticed that in order to preserve the quality of the vowels, that the diphthong needs to be created by minimal change in the jaw position, with the change in the vowel focused mainly on the movement of the tongue. This minimal jaw movement ensures a clean transition between the vowels. 
Here are some examples of diphthongs in the English language.

$[\mathrm{eI}]$ as in "hay"

Change, mainly, debạte, way, complicate, labbour, weight, bait, face, paint

[aI] as in "sky"

I, design, prime, wine, slight, died, aisle, tịme, height, apologịse, Chinna, cyclist

$[\mathrm{OI}]$ as in "noise"

Decoy, voice, buoy, coin, oyster, poison, moisture, royal, thyroid, appointment

[av] as in "cloud"

Compound, about, now, chowder, loud, bow, dowry, douse, town, sound

$[\mathrm{ov}]$ as in "go"

Broken, tone, over, owe, goes, home, bureau, no, froze, engross, approach

Throughout my training, I have learnt that diphthongs need to be built into the muscle memory in order to create a stable environment to glide between the two vowel sounds. Italian consists of predominantly pure vowels; however, English is littered with multisyllabic words. When singing, the stress should always be placed on the first vowel sound, elongating the sound, and quickly glossing over the second vowel sound. It is vital to practice the diphthongs in the rhythm that the word will be sung. Sometimes the unnatural elongation of the vowels due to the composer's notation of the rhythm can trick the performer into elongating both the vowel sounds. As a New Zealander who speaks predominantly English, I have the tendency to chew the vowels in a diphthong, directly transferring into my vocal technique when singing in English. Carefully analysing the vowel glide in the diphthong assisted in creating a smooth action to maintain a legato line. Rehearsing this action on a vowel stream (singing only the vowels) clearly outlines 
the pure vowels, allowing the mind and body to gradually learn the vowel pattern, before systematically adding in the consonants. In my experimentation for this study, I started adding in the consonants only when the vowel stream felt ingrained, focusing on the voiced consonants and then separately practicing the vowel stream with the unvoiced consonants. This process allowed me to clearly identify which consonants interrupted my vowels or distorted my pure vowel production.

Like all languages, English conforms to its own rhythm. These individual rhythms come from varied combinations of syllables that are long and short, stressed and unstressed. Rhythms within languages are also formed by the structure of the grammatical components of the sentence. When it comes to understanding English, arguably, this rhythm is as important as the proper pronunciation of vowels and consonants within the word. Understanding this rhythm impacts the stressed and unstressed nature of the words. To understand the rhythm within my English language repertoire, I spoke the text following my IPA to ensure the vowels were consistent and appropriately stressed, exactly replicating my process of performing repertoire written to be sung in Italian. Ensuring my pronunciation was correct assisted my progress when implementing bel canto principles. Legato line relies heavily on the production of vowel sounds, much easier to achieve in Italian, harder in English. Appropriate vowel sounds heavily impacted my ability to match the voice throughout my registers in line with the bel canto principles of voce mista and voce di petto. English vowels must remain consistent, without this there will be no possibility of creating a matched sound throughout. This matching is vital in achieving the bel canto principles of sostenuto, chiaroscuro, voce di petto and voce mista. Having explored each of the bel canto principles, my next step was to take a closer look at my recital repertoire written to be sung in English. In Chapter Four I analyse the effect that these principles had on a selection of this repertoire. 


\section{Chapter Four}

\section{$\underline{\text { Examination of selected works }}$}

Music auto-ethnographer Carolyn Ellis has shown that music performance and autoethnography have much in common. The core purpose of both is to "communicate engaging and personal tales through music and words, which inspire audiences to react, reflect, and, in many cases, reciprocate." ${ }^{116}$ In this chapter, I describe my progress and challenges faced in the application of the bel canto principles on a small selection of pieces written to be sung in English by composers Samuel Barber, Benjamin Britten, Aaron Copland, Lee Hoiby and Gian Carlo Menotti from my Master's Recital Repertoire.

In her book Singing in Style, Martha Elliott comments on Barber's continued sense of traditional Romanticism in his twentieth century compositions, which appealed to a varied audience. ${ }^{117}$ In relation to this, Elliott states "we don't really need to find a new style in order to sing it." "118 This presents the idea that the technique used generally today is based on nineteenth-century traditions, directly linking Barber's compositional style with bel canto compositional and vocal techniques. Therefore, I believe that every singer should be able to easily transfer the same skills through different genres and centuries of composition. However, how easy is it to transfer the bel canto techniques when it comes to the seemingly more demanding requirements of other twentieth-century compositions, which deviate further from the traditional bel canto style?

American composer Barber (1910-1981) belongs to the modern period of music composition. Occurring at the turn of the twentieth century, the defining feature of modern music is the breaking-down of traditional aesthetic conventions, thereby allowing complete freedom in all aesthetic dimensions, including melody, rhythm, and chord progression. Barber's works; however, do not conform to the atonal musical language common to other composers of his

\footnotetext{
${ }^{116}$ Music Autoethnographies: Making Autoethnography Sing/Making Music Personal, edited by Brydie-Leigh Bartleet, and Carolyn Ellis, Australian Academic Press, 2009. ProQuest Ebook Central, https:/ebookcentral.proquest.com/lib/vuw/detail.action?docID=634514. 6-7.

${ }^{117}$ Martha Elliott. Singing in Style. (Yale University Press, 2008) 282-295.

${ }^{118}$ Elliott. Singing in Style. 284.
} 
time. ${ }^{119}$ His compositional style is described as neo-classical, a genre through which composers sought to return to aesthetic precepts associated with the broad concept of 'classicism.' Barber studied the piano from a young age and in 1924 commenced his studies of piano and composition at the Curtis Institute of Music. He graduated in 1934, focusing purely on his music compositions. Barber's compositional style has been lauded for its musical logic, sense of architectural design, effortless melodic gift, and direct emotional appeal. ${ }^{120}$

Barber's works seem to stem from an emotional centre, each work communicating sincere emotion, rather than forcibly contorted dramatisations. It is suggested that this quality developed from his never-realised singing career, and his symbiotic friendship with Menotti, another natural practitioner of vocal writing, that augmented his instinctual gift. ${ }^{121}$ His literary taste, proficiency with language, and his unending melodic resourcefulness contributed to making his songs so personal. Barber's song 'Sure on this Shining Night' from his Four Songs, Op. 13, epitomises his emotional sincerity within the architecture of his composition. The musical lines are simple and controlled, centering around the communicative emotion of the text. The melody line mimics bel canto composition in its melodic lines supporting the typical bel canto aspect of beautiful legato and colourful sound. The overarching contour of the melody indicates the necessity for sustained breathing in order to support the extended vocal phrases. The sentences are long, and in order to connect the intention of the words, the words must be connected in a sustained manner. Management of the bel canto principles of sostenuto and appoggio was vital in crafting these melodic lines, connecting each syllable to the next.

When practicing the last line of Sure on this Shining Night, I struggled with sustaining the extended phrase, with only taking one breath within the ten bars so as to not interrupt the intention and flow of the text. ${ }^{122}$ I discovered the quality of the in-breath heavily affects the

\footnotetext{
${ }_{119}$ Don A Hennessee. Samuel Barber: a Bio-Bibliography. (Connecticut: Greenwood Press 1985) 125-132.

${ }^{120}$ Hennessee. Samuel Barber: a Bio-Bibliography. 15-22.

${ }^{121}$ Paul Wittke. Samual Barber, Claude Debussy - Long Biography - Music Scales Classical. (1994) www.musicsalesclassical.com/composer/long-bio/samuel-barber.

${ }^{122}$ The last line of Barber Sure on this Shining Night: Sure on this shining night I weep for wonder, wandering far alone of shadows on the stars.
} 
quality of the breath expelled whilst singing. This concept relates directly to the bel canto concept of appoggio, ensuring that the quality of the breath is adjusted in relation to the phrase sung. An extended in-breath allows me to completely 'fuel my tank', taking air into my lungs completely before starting the phrase. I also found that the first note is the most important of the phrase, as this note acts as the mould for the following notes. Typically, the start of a phrase is an unstressed vowel. Until I tried the breathing technique of appoggio, I usually started these phrases with an undernourished, unsupported production of sound. I realised that unstressed does not mean unsupported. Careful consideration of the text also heavily impacted my ability to craft the legato line needed. Crafting pure vowels (a vowel sound, where the articulation at both beginning and end is relatively fixed) was key in creating consistency throughout the entirety of the piece. Distorting the vowel production inhibits the audience's understanding of the word, heavily impacting the meaning. Vowel consistency creates a strong foundation to build on the innate emotion of Barber's work.

Another American, Menotti (1911-2007), is remembered as a composer of the old romantic tradition, which epitomizes the 'heart on sleeve' musical portrayal as if the age of Verdi and Puccini still existed. ${ }^{123}$ In 1928, he and his mother relocated to America from Italy so that Menotti could attend the newly opened Curtis Institute of Music in Philadelphia. A letter of recommendation from leading conductor and family friend Arturo Toscanini (1867-1957) made it possible for Menotti to study there. Toscanini was a performer and teacher who championed the dramatic operas of Verdi and Wagner and believed in keeping performers on a tight interpretive leash. The discipline instilled by his dictatorial mentor resulted in Menotti's clear understanding of compositional techniques, particularly of counterpoint. Perhaps Toscanini's compositional interpretation influenced his family friend Menotti's own composition style. The same discipline and training was experienced by another young composer, Barber, who became his close companion and lifelong friend.

\footnotetext{
${ }^{123}$ John Gruen. Menotti: A biography. New York: Macmillan, 1978. 1-15.
} 
Though Menotti's compositions are rather delicate in orchestration, they are vocally demanding in their lyric writing. Menotti's compositional style favours obscure vocal lines to depict the extremes of human emotion. The characteristic intervallic leaps create emotion within the contour of the melody, as extreme inflection in speech directly corresponds to heightened emotion. This vocal technique requires control over the passaggio, blending the entire range required for the composer's notation. This concept directly links to the bel canto principles of voce mista and voce di petto. When attempting the challenging intervallic leaps over the passaggio in Menotti's 'The Eternal Prisoner' from his Five Songs I found it difficult to maintain a matched sound from note to note. Separating the interval from the vocal phrase made it easier for me to specifically focus on matching the two notes together. The descending interval requires the bottom note to sound related to the top note. Maintaining the same space within my mouth helped me to create a consistent structure within which to produce the interval. I decided to relate the lower notes to the top note, rather than attempting to commence with a heavier sound at the top of my register. This required slow practice and awareness of the harmonic balance as I descended. Repeating the individual intervals created familiarity and secured a consistent vocal position. After each interval was secure, I would extend my focus to connecting three notes together. This controlled my descent in manageable sections, rather than trying to match the entire phrase all at once. Every phrase is different and requires individual work to create an overall matched tone throughout the performance.

It was a love of poetry that set Britten (1913-1976) on his path. His operas and vocal compositions are admired for their skillful setting of English words, their dramatic aptness and depth of psychological characterization. In his 1957 BBC radio interview with Joseph Cooper for the series, The Composer Speaks Britten identifies that it was his love of English poetry which directed him towards writing vocal music. ${ }^{124}$

\footnotetext{
${ }^{124}$ Joseph Cooper interview with Benjamin Britten. Paul Kildea, ed. Britten on Music. 'The Composer Speaks', (ist broadcast BBC general Overseas Service, 7 July 1957; pre-recorded 30 May 1957). (Oxford: Oxford University Press, 2003), 223-232.
} 
His understanding of the English language is evident in the speech-like quality of his word setting. The placement of the syllables within the musical contour clearly indicates which words are intended to be stressed and unstressed. In his setting of the famous 'Last Rose of Summer' Britten uniquely extends the second part of the phrases to depict the depth of emotion. ${ }^{125}$ Typically, he does this through extending the vowel in a melismatic passage on the last word of the phrase. This musical technique was frequently used in bel canto compositions. Undoubtedly bel canto composer Rossini's compositions require a sure technical foundation which enables the singer to navigate the long complicated melisma or coloratura sections. ${ }^{126}$ The voice needs to be incredibly flexible, almost instrumental, like a flute or an oboe and there also needs to be a lightness to the sound. This same method is required in Britten's vowel extensions in order to ensure that each note is matched to the last. Perhaps, this was Britten's way of surprising the listener, instead of conforming to the traditional folk song expectation of one note per word. Britten's extended melismatic phrasing adds interest through the vocal dexterity, harking back to the bel canto compositional method of emotional expression.

Most of Britten's 'Last Rose of Summer' sits over or just above my second passaggio and requires concentrated stability in order to fully support the voice over this transitional area. As I became frustrated, the less supported and overblown the sound was. Practicing the action softly allowed me to focus on the sensation, rather than the sound. I knew if the voice felt free and open when singing softly, when I projected, the sound would remain so. This gradual practice allowed me to ease over my passaggio, inviting my registers to blend. As mentioned earlier, I initially considered Mengozzi's idea of sweetening the last note before the passaggio transition, but found this provided more confusion than solution. I felt this idea encouraged a change of timbre, rather than a matching of registers. After attempting to implement this concept over scalic passages I came to the realisation that perhaps this method was intended to encourage the registers to be influenced by the other. Instead of considering my vocal registers as separate entities, it occurred to me that the colour of the lower register may need to have more brilliance

\footnotetext{
${ }^{125}$ Britten's setting of 'The Last Rose of Summer' is the ninth piece from his Folksong Arrangements, vol. 4 : Moore's Irish Melodies.

${ }^{126}$ Celletti and Fuller. A History of Bel Canto. 135-178.
} 
in order to match the shimmer of the upper register. The concept of sweetening could then be useful not only affecting the passaggio transition, but also in implementing the bel canto principle of voce mista.

Celebrated as a song writer covering many genres, twentieth-century American composer Hoiby is known for having composed tonal, lyrical music in a time when his peers were exploring serialism and atonality. ${ }^{127}$ Now regarded as an important contributor to American music, Hoiby composed songs, operas, and choral works as well as instrumental and chamber music. His compositions are especially revered by singers, many of whom state that Hoiby was gifted at writing highly crafted songs because he "knew the voice". ${ }^{28}$ Hoiby's Winter Song from his Songs for Leontyne requires extended breath control to fulfill the lengthy phrases, whilst utilising the lower part of the singer's register. As mentioned earlier, the lower part of my voice has always been described as earthy and full; however, I know that sometimes the excitement of exploring this part of my voice, can lead me to over-indulge and force the sound, which disconnects my lower vocal quality from my upper register.

Utilising voce mista encouraged me to combine the chest and head registers together by use of more laryngeal tilt. This laryngeal tilt allows for the extension of a singer's range upwards, whilst preserving the vocal quality and colour from the lower register. Laryngeal tilt is the position where the cricothyroid muscle is actively engaged and the thyroid cartilage is rotating forward. The thyroid cartilage is connected to the cricoid cartilage, both of which can rotate relative to each other, along the axis of the cricothyroid joint where both cartilages connect. Classical singing training encourages a slight lowering of the larynx for increased warmth of tone, with a simultaneous 'tilting' forward of the thyroid cartilage. Laryngeal tilt helps to create more space for the vocal cords, aiding passaggio transitions by allowing the vocal cords to stretch and slacken freely. Laryngeal tilt also creates a vibrato in the sound, producing multiple colours

\footnotetext{
${ }^{127}$ Lori Ellefson Bade. Lee Hoiby: the Composer and His Compositional Style, His Role in the History of American Music, and His Song Output. (Austin: University of Texas, 1994) 1-32.

${ }^{128}$ Gayle Worland. Lee Hoiby: A Great Composer Who 'Knew the Voice'. Madison.com, Madison, 2 Apr. 2011, madison.com/wsi/news/local/lee-hoiby-a-great-composer-who-knew-the-voice/article 76360eb4-7a1a-528c-8227-3 $\underline{2 \mathrm{c} 0520 \mathrm{~d} 0077 . \mathrm{html}}$.
} 
within a free sound. When working on this piece, in order to find the proper placement for my lower register, I started by speaking the text in rhythm, mentally analyzing the sound quality and the physical effort required. Then I spoke the words at pitch in a tilted laryngeal position before transitioning into singing the vocal line. The vocal quality produced sounds almost like a puppy whimper, requiring full false vocal fold retraction and maximum tilt. I found that moving directly from speaking to singing created a more connected sound throughout my range. Speaking in laryngeal tilt made the transition from neutral to a forward vocal placement easier. Speaking the text of the music (orating on pitch) allows the performer to assess the quality of their tone, focusing their full attention on the way the words are said: declamato. ${ }^{129}$

As mentioned previously, declamato was an important part of the castrati vocal technique in the sixteenth century, focusing on the blending of tonal characteristics between the spoken and sung voice. $^{130}$ The use of the declamato encouraged me to integrate the core qualities of my spoken performance into my sung performance. When orating the text, I noticed the relaxed, stable laryngeal positioning where the voice originates from the core, connecting the sound to the body. The vocal quality was natural rather than a fake veil placed on top. This exercise also revealed the effort required from the body to sustain the lower resonance. The body is the vocal instrument, breath must be connected to the physical support in order for the voice to move freely and remain harmonically consistent throughout multiple registers.

Copland (1900-1990) was an American composer, composition teacher, writer, and later a conductor of his own and other American music. Referred to by his peers and critics as the Dean of American Composers he epitomised the ideals of American composition. Copland's teacher and mentor Nadia Boulanger became his most important influence. ${ }^{131}$ Copland admired Boulanger's understanding of all genres and styles of classical music, and he was encouraged to experiment and develop a "clarity of conception and elegance in proportion." ${ }^{132}$ Following her model, he studied all periods of classical music and all forms. Boulanger particularly emphasized

\footnotetext{
${ }^{129}$ Stark. Bel Canto: a History of Vocal Pedagogy. 31.

${ }^{130}$ Rice. A Cry to Heaven: a Novel. 15.

131 Julia Smith. Aaron Copland: His Work and Contribution to American Music. (Dutton, 1955) 1-10.

${ }^{132}$ Smith. Aaron Copland: His Work and Contribution to American Music. 5-16.
} 
la grande ligne (the long line), "a sense of forward motion ... the feeling for inevitability, for the creating of an entire piece that could be thought of as a functioning entity." ${ }^{133}$

This awareness is clearly evident in Copland's composition 'Laurie's Song' from his opera The Tender Lands where the breadth of the vocal line mimics Laurie's emotional and physical journey towards her high school graduation. Whilst the tune may appear simple, once again this composition requires control over the passaggio, demanding a blended sound throughout. I experimented with singing a phrase only on the starting pitch, and then repeated the phrase singing only on the final pitch of the phrase. This clearly displayed the difference in my harmonic structure between the two notes, for example; the first phrase between $\mathrm{B}^{\prime}$ and $\mathrm{E} 4{ }^{\prime}$ (Helmholtz). Gradually working up the scale from the lowest note in the phrase to the highest allowed me to adequately manage my passaggio, matching the harmonics throughout. Chiaroscuro was vital in portraying the emotional journey and maintaining the full harmonic spectrum of colours throughout. Recording the sounds for myself was crucial in determining if the emotional content was appropriate and if the sound was authentic and touching, given it is the colour of the sound which creates the strongest impact on the listener. While we as listener think that we comprehend the text first, the latest research suggests that the sound we hear is not only heard, but also processed first and the body gives an immediate reaction.

In Carolyn Timmsen Amory's article ‘Apprehending the live voice: hearing and prehearing', she comments on the bodily reaction to live vocal performance. ${ }^{134}$ Amory suggests that the body reacts to the sound before the mind has had time to process the vocal sound created by the performer. ${ }^{135}$ A relatable example of this concept is hearing a scream, automatically associated with danger, whether intelligible or not. This stresses the importance of a performer colouring the sound with emotional intention so the audience has an immediate reaction to the sound, automatically creating a deeper connection between the audience and the performer. Like the

\footnotetext{
${ }^{133}$ Howard Pollack. "Aaron Copland: The Life \& Work of an Uncommon Man. (1999) 49-57. (New York: Henry Holt and Company, 1999) 49.

${ }^{134}$ Carolyn Timmsen Amory. “Apprehending the Live Voice: Hearing and Prehearing.” Journal of Singing (May, June 2011, Volume 7, no.5) 16-32.

${ }^{135}$ Timmsen Amory.“Apprehending the Live Voice: Hearing and Prehearing.” Journal of Singing. 16-32.
} 
physical choices made by the performer regarding intention and impulse, decisions concerning the colour of the sound produced are vital in creating a connected performance. Prior to reading Amory's article, I had always placed fairly even importance between the sound created and the physical actions crafted. Amory encouraged me to question this assumption. Her research informs us that the sound potentially holds more importance than the physical action. Chiaroscuro assists in creating tangible emotion for the audience, as the whole spectrum of colours is available for the performer to utilise. 


\section{Conclusions and moving forward}

Bel canto principles provide the tools for superb technique and I believe these should form the foundation of all classical vocal training. While my research focused on the application of these principles on twentieth-century repertoire written to be sung in English, I believe they are transferable to classical vocal compositions from any period.

My study of the processes and application of bel canto principles has shown that the principles of the bel canto singing style help in forming the foundation of a secure vocal technique. These principles assisted me in managing my technical deficiencies, whilst creating a universal base to approach contrasting periods of music. This new understanding has encouraged me to approach new music from a technical standpoint, building a strong base of technique over which to layer the intricate details of emotion for communication, which I will demonstrate through my two recitals at the end of my study period. A lot of existing works on bel canto approach the style from a sensory level, focusing purely on how the sound feels and what the effect is on the sound. Even the early treatises do not provide a practical guide to achieving the desired effects of the bel canto principles. It has only been through reading multiple guides and histories that I have been able to understand what it is that needs to take place in the practice room in order to achieve the bel canto principles. I did not expect the challenges I faced in the application of these principles, but found that these challenges could be overcome through slow and dedicated practice.

Critical analysis forced me to strengthen my technique through trial and error, testing multiple approaches to find which perspective worked for me. I have noticed a significant difference in my vocal technique, as I now have a clearer understanding on how to apply and maintain these bel canto principles. My registers are more blended and I am able to manage my passaggi with increasing ease. In my recital I will utilise these skills to create multiple colours in my tone production, with my newly strengthened vocal technique. I will sing the compositions set in English with an Italianate approach to maintain an overall legato line and matching of vowels. 
My research has been a practical learning process which is far from over, and continuing to hone in on these principles and approaches will benefit me as a performer. My research has shown the applicability of the bel canto principles to modern twentieth-century repertoire written to be sung in English. The bel canto principles of sostenuto, messa di voce, appoggio, chiaroscuro, voce mista and voce di petto are relevant for the modern day singer learning vocal compositions from any period. I firmly believe that these principles provide the tools to perform all music with beauty. Taking into account my small selection of works written by Barber, Britten, Copland, Hoiby and Menotti, the transference of these principles is clearly applicable.

As a young singer pursuing a career in opera, I feel that it is vital to be versed in the bel canto principles in order to be able to perform bel canto repertoire with accomplishment. Although vocal technique is ever evolving and new styles of singing are constantly developing in the Western culture, it is clear that modern classical singers need to form a solid technical skill base that enables them to transcend multiple genres and styles of vocality. In addition to the benefit to me and other singers and teachers of this research, performance and study of such works from the twentieth-century supports the continued development of opera and other classical vocal genres, as music from the twentieth-century is vital for their continuation. 


\section{APPENDIX: GLOSSARY OF TERMS}

Appoggio: from appoggiare to lean. In bel canto singing it refers to the sustained breathing technique, predominantly focusing on maintaining the inhalation position of the ribcage.

Autoethnography: qualitative research in which the author uses self-reflection and writing to explore anecdotal and personal experience. This method is used to connect the author's autobiographical story to a wider audience.

Chiaroscuro: a bel canto principle which is the combination of a brilliant sound referred to as chiaro or squillo and a dark timbre called oscuro.

Coloratura: fast moving passages and elaborate ornamentation of the vocal melody.

Declamato: is the blending of tonal characteristics between the spoken and sung voice.

Fioritura: from the Italian 'flowering', or 'to flourish.' Fioritura is the florid embellishment of melodic lines, either notated by a composer or improvised and interpreted by the performer.

Legato: singing in a smooth flowing manner, without breaks between notes in a musical phrase.

Melisma/melismatic: implies a group of notes sung on one syllable. The term is used to describe a phrase which incorporates a melisma.

Messa di voce: the performer begins the note with little colour, and then increases the intensity with a simultaneous deepening of colour.

Passaggio: is used in classical singing to describe the transitional area between vocal registers.

Portamento: from the Italian verb 'to carry.' Where a musician gracefully slides from one pitch to another.

Schwa: [ə] a neutral vowel where the mouth shape is similar to the short [u] vowel but smaller. The position is created with neutral lips, paired with the centre of the tongue placed centrally in the mouth.

Sostenuto: sustaining sounds tied together to create an unending flow of sound. 
Tessitura: the range that a voice type is most comfortable singing in or the range that a piece mostly sits in.

Timbre: the quality and characteristic of a musical sound.

Velopharyngeal Port: the opening between the nasopharynx and oropharynx.

Velum: the soft palate, a moveable fibromuscular structure that is attached to the posterior border of the hard palate.

Verismo: from the Italian vero, meaning 'true': a post-Romantic realistic operatic tradition marked by melodramatic scenarios, often featuring violent plots with characters drawn from everyday life.

Vibrato: derived from the Italian vibrare, to vibrate. This vocal effect is created by degrees of laryngeal tilt and is closely associated with classical voice performance.

Voce di petto: the matching of the voice from the middle register through the chest voice, smoothing the passaggio break and maintaining the harmonic structure and tone of the middle register when moving up or down through the middle voice.

Voce mista: mixed voice. It involves mixing the chest and head registers together by way of using more laryngeal tilt to allow the singer to carry lower resonance up through their upper registers.

Voce di testa: relating to vocal registers, particularly referring to the head/falsetto register.

Voix de poitrine: refers to as the female's chest voice. See entry for 'Registers.'

Voix de tête: refers to the head voice in female vocal registration. See entry for 'Registers.'

Voix $d u$ gorge: refers to as the female's throat voice, what we consider the middle register. See entry for 'Registers.' 


\section{Bibliography}

Abbate, Carolyn and Parker, Roger, A History of Opera; the last four hundred years, New York: Penguin Group, 2012.

Bade, Lori Ellefson. Lee Hoiby: the Composer and His Compositional Style, His Role in the History of American Music, and His Song Output. Austin: University of Texas, 1994.

Baldy, Colin. The Student Voice: an Introduction to Developing the Singing Voice. Edinburgh: Dunedin Academic Press, 2010.

Bartleet, Brydie-Leigh and Ellis Carolyn. Music Autoethnographies: Making Autoethnography Sing/Making Music Personal, Australian Academic Press, 2009. ProQuest Ebook Central.

Barnett, John. School for the Voice or the Principles of Singing. Addison \& Hodson, 1845.

Bernhart, Walther and Lawrence Kramer, eds, On Voice, New York: Rodopi, 2014.

Caccini, Giulio. Le Nuove Musiche: Firenze, 1601 (Recte 1602), 1614, Venezia, 1607, 1615. Cornetto, Gedruckt in Lizenz Von Musedita, 2006.

Caruso, Enrico and Tetrazzini, Luisa On the Art of Singing, New York, Dover, 1975.

Celletti, Rodolfo, History of Bel Canto, Oxford, Clarendon Press, 1991.

Christiansen, Rupert. Singing in English: It's harder than you think. (Telegraph.co.uk, 2013). https://www.telegraph.co.uk/culture/music/opera/10053327/Singing-in-English-Its-harder -than-you-think.html

Coffin, Berton, Historical Vocal Pedagogy Classics, Maryland: The Scarecrow Press, 2002.

Crutchfield, Will, Vocal ornamentation in Verdi: The Phonographic Evidence, Nineteenth Century Music, Vol 7, No.1 (Summer, 1983).

Elliott, Martha. Singing in Style. Yale University Press, 2008.

Esse, Melina, Elizabeth, Sospirare, tremare, piangere: conventions of the body in Italian opera ProQuest Dissertations and Theses, 2003.

Esse, Melina. “Chi piange, qual forza m'arretra?”: Verdi's interior voices, Cambridge Opera Journal, 14, 1\&2, 2002.

Estill, Jo, et al. Estill Voice Training: Level One Figure for Voice Control: Workbook. Estill Voice Training Systems International, 2010.

Fagnan, Laurier. The Impact of Bel Canto Principles on Vocal Beauty, Energy and Health Podium 2010 https://www.ualberta.ca/campus-saint-jean/-/media/csj/recherche/bel-canto-vocal-principl es.pdf. 
Freitas, Roger, Towards a Verdian Ideal of Singing: Emancipation from Modern Orthodoxy, Journal of the Royal Musical Association, Vol 127, No. 2, 2002, pp 226-257.Garcia, Manuel. Memoire Sur La Voix Humaine. Duverger, 1847.

Gardiner, William. The Music of Nature. Cambridge University Press, 1989.

Grove, George, and J. A. Fuller-Maitland. Grove's Dictionary of Music and Musicians. 1st ed., General Books, LLC, 2012.

Gruen, John. Menotti: A biography. New York: Macmillan, 1978.

Henderson, William James, Art of the Singer. New York: Rarebooksclub Com, 2012.

Hennessee, Don A. Samuel Barber: a Bio-Bibliography. Greenwood Press, 1985.

Hines, Jerome. Great Singers on Great Singing. Wisconsin: Limelight, 2006.

Hoeler, Mark, director. Luciano Pavarotti Speaks about Concentration, Diaphragm, Throat, Resonance. 2016, www.youtube.com/watch? $\mathrm{v}=0 \mathrm{gp} 35$ OUFBlk.

Howlett, Neil. Vocal style in Wagner from the Golden Age to the Present - Lower Male Voices Neil Howlett. (2015) Neil Howlett. Available at: http://neilhowlett.com/articles/vocal-style-in-wagner-from-the-golden-age-to-the-presentlower-voices/

Kildea, Paul. Joseph Cooper interview with Benjamin Britten.. Britten on Music. 'The Composer Speaks', (ist broadcast BBC general Overseas Service, 7 July 1957; pre-recorded 30 May 1957). (Oxford: Oxford University Press, 2003), 223-232.

Klimek, Mary McDonald, et al. Estill Voice Training System. Workbook, Level Two. Estill Voice Training Systems International, 2005.

Klimek, Mary McDonald, et al. Estill Voice Training System, Level One: Figures for Voice Control: Workbook. Estill Voice Training System, 2005.

Lamperti, Giovanni Battista. The Technics of Bel Canto. Pitch Perfect Publishing, 2010.

Libermann, Alexander. "How to Practice." How To Practice, howtopractice.com/music-practice-quotes.(2000)

Mancini, Giambattista. Pensieri, e Riflessioni Pratiche Sopra Il Canto Figurato. Italy: Stamparia Di Ghelen, 1774.

Manén, Lucie. The Art of Singing: a Manual of Bel Canto. London: Faber, 1981.

Marchesi, Mathilde, Bel Canto: A Theoretical and Practical Vocal Method, New York: Dover, 1970.

Mengozzi, Bernardo, et al. Méthode De Chant Du Conservatoire De Musique De Paris En Trois Parties: Première Partie. Breitkopf \& Haertel, 1893.

Miller, Richard. On the Art of Singing. New York: Oxford Univ. Press, 2011. 
Miller, Richard. National Schools of Singing: English, French, German, and Italian Techniques of Singing Revisited. Lanham, MD: Scarecrow Press, 2002.

Miller, Richard. Training Soprano Voices. Oxford University Press, 2000.

Noske, Frits, The Signifier and Signified, Den Haag, Martinus Nijhoff, 1977.

Pleasants, Henry, The Great Singers, New York: Simon and Schuster, 1966.

Pollack, Howard. Aaron Copland: The Life \& Work of an Uncommon Man. New York: Henry Holt and Company, 1999.

Reid, Cornelius L, Bel Canto: Principles and Practices. J. Patelson Music House, 1990.

Rice, Anne. A Cry to Heaven: a Novel. Ballantine Books, 2015.

Robbin, Catherine “Appoggio Demystified”, York University, Ontario, Canada, http://journals.library.mun.ca/ojs/index.php/singing/article/viewFile/1035/889

Rosselli, John, The Life of Verdi, Cambridge University Press, 2000.

Rosselli, John, Singers of Italian Opera: The history of a profession, Cambridge University Press. 1992.

Rutherford, Susan, "Voices and Singers." The Cambridge Companion to Opera Studies, edited by Nicholas Till. Cambridge, Cambridge University Press, 2012, 121.

Smith, Julia. Aaron Copland: His Work and Contribution to American Music. Dutton, 1955.

Stark, James, Bel Canto: A History of Vocal Pedagogy, Toronto: University of Toronto Press, 1999.

Striny, Denes. Head First: the Language of the Head Voice: a Concise Study of Learning to Sing in the Head Voice. Hamilton Books, 2007.

Toft, Robert, Bel Canto: A Performer's Guide, USA: Oxford University Press, 2012

Tosi, Pier Francesco, and Gregory Blankenbehler. Observations on the Florid Song: or, Sentiments on the Ancient and Modern Singers. Pitch Perfect Pub., 2009.

White, Eric Waller. Benjamin Britten: a Sketch of His Life and Works. Boosey \& Hawkes, 1949.

Wittke, Paul. "Samuel Barber." Claude Debussy - Long Biography - Music Sales Classical, 1994, www.musicsalesclassical.com/composer/long-bio/samuel-barber.

Worland, Gayle. “Lee Hoiby: A Great Composer Who 'Knew the Voice'.” Madison.com, Madison, 2 April 2011, madison.com/wsj/news/local/lee-hoiby-a-great-composer-who-knew-the-voice/article_76 360eb4-7ala-528c-8227-32c0520d0077.html. 